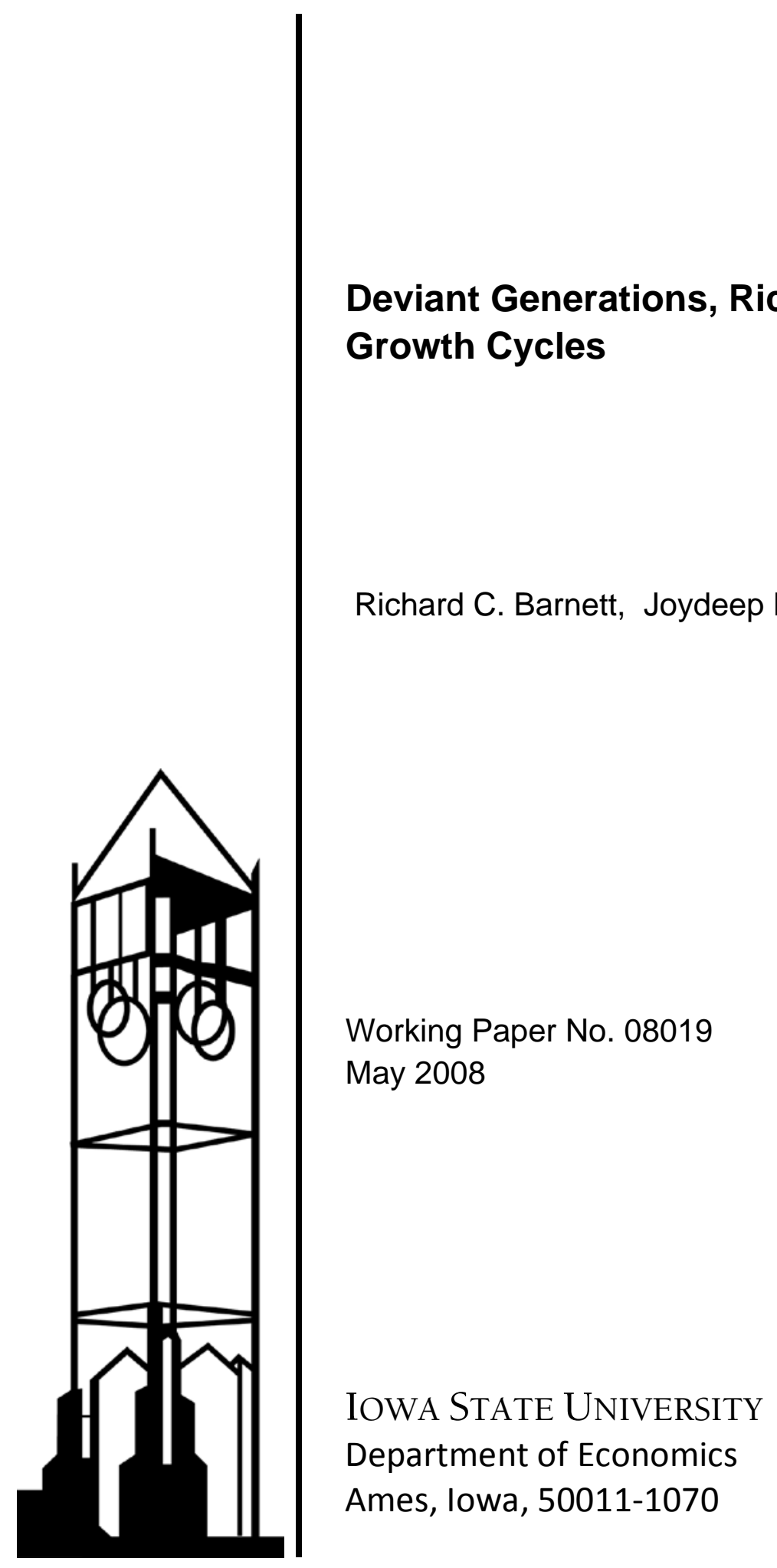

lowa State University does not discriminate on the basis of race, color, age, religion, national origin, sexual orientation, gender identity, sex, marital status, disability, or status as a U.S. veteran. Inquiries can be directed to the Director of Equal Opportunity and Diversity, 3680 Beardshear Hall, (515) 294-7612. 


\title{
Deviant Generations, Ricardian Equivalence, And Growth Cycles
}

\author{
Richard C. Barnett \\ Drexel University \\ Joydeep Bhattacharya*\& Helle Bunzel \\ Iowa State University
}

Revised June 3, 2010

\begin{abstract}
Two equilibrium possibilities are known to obtain in a standard overlapping-generations model with dynastic preferences: either the altruistic bequest motive is operative for every generation (in which case, Ricardian equivalence obtains) or it is not, for any generation. Dynamic equilibria, where the bequest motive is occasionally operative, cannot emerge. This paper studies bequest-giving behavior and out-of-steady-state bequest and growth dynamics in a $A k$ model with intra- and intergenerational consumption externalities. These externalities, by their very presence, do not destroy Ricardian equivalence. They may, however, give rise to deviant generations - generations that do not leave a bequest having received an inheritance, and vice versa and that seals the fate for Ricardian equivalence. Consumption externalities may also generate interesting indeterminacies and endogenous growth cycles that did not exist otherwise.
\end{abstract}

Keywords: consumption externality, bequests, Ricardian equivalence, growth cycles JEL Classifications: E 13, E 32

\footnotetext{
${ }^{*}$ Corresponding author: Joydeep Bhattacharya, Department of Economics, 260 Heady Hall, Iowa State University, Ames IA 50011; Ph: (515) 294 5886; Fax: (515) 294 0221; E-mail: joydeep@iastate.edu
} 


\section{Introduction}

It is well accepted that parents influence the behavior of their children. For example, parents set a benchmark consumption level urging their children to aspire to that level and beyond (see, for example, de la Croix and Michel, 2002). Another direct channel of parental influence on children is via transfers they make. This has received prominent attention in the arena of public policy, especially in the context of Ricardian equivalence, the invariance of an individual's consumption decisions to changes in lump-sum taxes.

It is standard fare (see Aiyagari, 1992) in most models of infinitely-lived agents that Ricardian equivalence holds. On the other hand, in the domain of infinite-horizon economies with finitely-lived agents, discussions surrounding Ricardian equivalence take on a specific form: researchers endow agents with dynastic preferences and ask, Under what conditions is the altruistic bequest motive - the transfer of resources from parents to children motivated by parental altruism - operative? For if it is and at every date, as Barro (1974) and Weil (1987) have argued, Ricardian equivalence again obtains - altruistic parents simply neutralize any change in the present value of their children's taxes via appropriate transfers.

This paper analyzes how within and across generation consumption externalities affect the evolution of the altruistic bequest motive across generations. It is part of a line of inquiry dating back to the early contributions by Weil (1987) and Abel (1987) - and more recently, Michel et. al (2006), Abel (2005), and Alonso-Carrera et. al. (2008) - into the operativeness of the bequest motive in overlapping-generation economies. A main focus of this literature is the existence of a steady state with positive bequests in the textbook version of Diamond's (1965) overlapping generations model, one with a concave, neoclassical technology. Our principal value-added is a detailed analysis of the out-of-steady-state bequest and growth dynamics in a fairly-standard $A k$ model. Such a study exposes the novel possibility of deviant generations, those whose bequest-giving behavior diverges along the extensive margin from that of their parents. And it is the phenomenon of deviant generations, not consumption externalities per se, that nullifies Ricardian equivalence. 
Our analysis begins, in Section 3, with a study of bequests in a benchmark model, one sans intra and intergenerational consumption externalities. Here, we show that the bequest motive is operative if and only if the expected future growth rate exceeds a certain threshold, or equivalently, if and only if the factor measuring the degree of altruism - the utility weight placed by a parent on her child's well-being - is sufficiently high. Next, echoing the discussion in Abel (1987) and Aiyagari (1992), we prove another important result for the benchmark model: either the altruistic bequest motive is operative for every generation or it is not for any generation. The prospect of generating intergenerational differences in bequest-giving behavior along an extensive margin - some generation may leave a bequest, itself not having received an inheritance, or vice versa - simply does not arise. ${ }^{1,2}$ In short, deviant generations are not possible in the benchmark model. Parenthetically, the only equilibria are stationary: depending on the value of the altruism factor, the economy is either instantly at a steady state in which the bequest motive is operative at each date or it is not. In short, there is a unique equilibrium; no indeterminacies, transitional dynamics, volatility in the growth rate, nor deviant generations, are possible in the benchmark model.

In Section 4, we introduce within and across generation consumption externalities in the model. At first glance, it may seem that any and all such externalities automatically ring the death knell for Ricardian equivalence. After all, the Ricardian Equivalence Theorem is valid under a fairly stringent set of assumptions (intergenerational altruism, perfect capital markets, lump-sum taxation, exogenous fertility, and so on), and any important deviation, such as the introduction of externalities, ought to be sufficient to invalidate it. ${ }^{3}$ We show

\footnotetext{
${ }^{1}$ Most models with finitely-lived agents restrict attention to equilibria in which the bequest motive is operative at all dates. Generally, such models generate intergenerational differences in bequest-giving along an intensive margin - some generation leaves more, some leave less. None of them exhibit aforediscussed differences - emerging endogenously - along an extensive margin. Our setup is capable of generating disparities along both margins.

${ }^{2}$ Intergenerational differences in bequest-giving have wide-ranging implications well beyond their effect on Ricardian equivalence. Bequests constitute an important channel for capital accumulation. They are a major channel for the transmission of wealth across generations; as such, intergenerational differences in bequests have the potential to perpetuate wealth inequality across generations. For a recent tratement of this last issue, see Alvarez-Cuadrado and Long (2009).

${ }^{3}$ Also see Bossi and Porqueras (2010) who, in a somewhat different setting, make a case against Ricardian
} 
that is not the case. Indeed, a unique equilibrium exists in which the bequest motive is operative at each date, provided the altruism factor is sufficiently high. Here, Ricardian equivalence holds.

Three additional items deserve mention here. First, the equilibrium growth rate in the model with consumption externalities under a operative bequest motive is exactly equal to its counterpart in the benchmark model. The implication is that when the bequest motive is operative at each date, the presence or absence of consumption externalities has no effect on the growth rate. Second, we ask: Is it possible that Ricardian equivalence does not obtain in the benchmark economy and yet, it does, in the corresponding model with consumption externalities? We find, under a simple sufficient condition, the answer is, yes. The presence of consumption externalities may have the potential to "jump start" bequest-giving, with concomitant implications for the neutrality of tax policy.

Finally, somewhat curiously, when the altruism factor is not too high, the model can only generate equilibria in which the bequests are passed along for finitely-many consecutive dates; importantly, it cannot support growth paths in which the bequest motive is operative asymptotically. As a consequence, Ricardian equivalence does not hold in the long run. And yet, bequests are left and received by arbitrarily many generations, just not each and every one. This is in sharp contrast to what transpires in the benchmark model where either bequests are left and received by each and every generation or they are not for any generation. We show that deviant, out-of-steady state equilibrium paths — paths where any one particular generation does not leave (receive) a bequest even though their predecessors did (did not), nor do their progeny wish to replicate the bequest-giving behavior of their parents - exist. Heuristically, this may happen, for example, when members of one generation, having received an inheritance from the previous generation, chooses not to leave a bequest to the next, especially if they are trying hard to keep up with the latter's consumption. When parents feel the need to keep up, there is a natural tension between equivalence under the assumption of intertertemporally non-separable preferences. 
leaving a bequest to children (which presumably raises the childrens' consumption) and not leaving one (which keeps the childrens' consumption low and hence easier to emulate). In Section 5, for example, we show the existence of a 3-period limit cycle in the growth rate. In such a cycle, a generous but deviant Generation $t$ (one that receives no inheritance but leaves a bequest), may be followed by a 'normal' Generation $t+1$ (one whose bequest decision is similar to their parents - and in this case, leaves a bequest), and a stingy deviant (a Generation $t+2$ that receives an inheritance but leaves no bequest), before coming full-circle to a new, generous Generation $t+3$. A non-negativity constraint on bequests - parents cannot legally commit their children to assume debts on their behalf — which binds for some generations, is critical in generating these cyclical patterns of gift-giving.

Why might the possibility of deviant generations be of interest? The reason is that Ricardian equivalence requires “....all generations be linked by operative-intergenerational transfer motives. If some generation has no operative-intergenerational transfer motive, then at least some changes in the timing of lump-sum taxes will affect the intertemporal allocation of resources." [Abel, 1987]. Abel had not demonstrated the existence of such deviant generations; indeed, Michel et al (2006, Section 3.2) study the dynamics for an economy identical to one studied in Abel (1987) and conclude that "the possibility to switch from a temporary equilibrium with positive bequests to a temporary equilibrium with zero bequests along the transition path is excluded in the Cobb-Douglas economy." 4 By establishing the existence of deviant generations, we provide an example - the first to our knowledge - that supports Abel's hypothesis regarding the breakdown of Ricardian equivalence..$^{5}$ In sum, intergenerational consumption externalities, by their very presence,

\footnotetext{
${ }^{4}$ Indeed, in their Handbook chapter, Michel et. al (2006) suggest "analysing dynamics switching between a temporary equilibrium with positive bequests and a temporary equilibrium with zero bequests is an issue for future research."

${ }^{5}$ It deserves mention here that deviant generations arise endogenously in our framework; unlike Dutta and Michel (1998) or Michel and Pestieau (1998) or Aiyagari (1992), we do not impose any heterogeneity in altruism or discount factors.

A type of deviant generations arises in the analysis of Abel (1988) and de la Croix and Michel (pg. 255, 2002). There, a temporary increase in government spending is financed by an increase in the tax on old households of a particular generation thereby driving that generation to a zero-bequest corner. Even in this
} 
do not destroy Ricardian equivalence. They may, however, generate the phenomenon of deviant generations, which in turn, nullifies Ricardian equivalence.

The analysis, in the spirit of Liu and Turnovsky (2005), also uncovers important implications for indeterminacies. As demonstrated in the paper, in the model with consumption externalities, the relationship between the current and future growth rate is a correspondence (any value of the current growth rate is consistent with two values of the future growth rate). This means, given the current growth rate, the actions of perfect-foresight agents can lead to either high or low growth rates the following period. Hence, along two equilibrium sequences that emanate from the same initial condition, the time series of growth rates may look very different. The upshot for convergence is that countries that "look similar" at some point in time, may end up looking very different, in the future. It is evident that consumption externalities are responsible for these indeterminacies, since the latter do not appear in the benchmark model.

It is of independent interest that the economy we study is capable of generating limit cycles of varying periodicities - including three and higher period cycles - in the growth rate. In the literature, virtually all models that generate growth cycles are technology, not preference, driven (see, for example, Matsuyama (1999) or Walde (2005)). In our model, periodic equilibria in the real growth rate emerge in a relatively standard economy; indeed, absent the non-negativity constraint on bequests, the model economy does not produce endogenous fluctuations of any kind. ${ }^{6}$ These cyclical equilibria tell important stories of non-convergence in bequest-giving patterns across economies. In our setup, depending on

financing scenario, the bequest motive is operative in the long run.

${ }^{6}$ Ours is not yet another paper demonstrating the presence of indeterminacies in overlapping generation (OG) models. It is clear that the OG nature of the model is not responsible for the indeterminacies we demonstrate since these do not appear in the benchmark model.

Similarly, there is a vast literature studying the possibility of complex dynamicss - periodic (even chaotic) equilibria in overlapping generations models. Most of that literature is concerned with studying nominal cycles (i.e., fluctuations in price levels). The rest of that literature has focused on studying cycles in the levels of the capital stock or output. To the best of our knowledge, the current paper is the first to show existence of high-order cycles in the growth rate via the preference route (and that too, in a reasonably standard economy). 
initial conditions, generations in Economy I may leave a bequest at finitely-many successive dates, while those in Economy II (starting off with slightly different initial conditions) may perpetually vacillate, some leaving a bequest and others not.

Finally, it may seem that consumption externalities do little more than generate consumption floors for various generations, and that replacing all such externalities by a simple generational minimum consumption requirement (one that tracks the growing economy, such as in Álvarez-Peláez and Díaz, 2005) would be sufficient to generate all the results, including the possibility of deviant generations. We prove this is not the case. In Section 6 , we prove that the qualitative properties of such an economy are identical to that of the benchmark model - the one sans consumption externalities.

\section{Environment}

Consider an economy populated by an infinite sequence of two-period lived overlapping generations and an initial old generation. At each date, $t=1,2,3 \ldots$, a new generation is born; each consists of a continuum of agents with mass 1. Each agent, starting with Generation 1, has one unit of time when young and retires when old. Each initial old agent is endowed with $k_{1}>0$ units of capital. At the start of each date $t$, an old agent (potentially) passes on a bequest of amount $b_{t-1}$ to her offspring. We assume agents face a non-negativity constraint on bequests - meaning, of course, that a parent has no legally binding way to extract a gift from her offspring. Of particular interest here is the conditions under which this constraint will, and will not, bind. We say that the bequest motive is operative at date $t$ whenever $b_{t}>0$.

The sole final good of the economy is produced using a production function $F\left(K_{t}, L_{t}\right)$, where $K_{t}$ denotes the capital input and $L_{t}$ denotes the labor input at $t$. Let $k_{t} \equiv K_{t} / L_{t}$ denote the capital-labor ratio (capital per young agent). Output per young agent at time $t$ may be expressed as $y_{t}=f\left(k_{t}\right) ; f\left(k_{t}\right) \equiv F\left(K_{t} / L_{t}, 1\right)$ is the intensive form. The final good is either be consumed in the period it is produced or it can be stored to yield capital the 
following period. For analytical tractability, capital is assumed to depreciate $100 \%$ between periods.

We assume a standard $A k$ model with a Romer-style externality. Specifically, $Y_{t}^{i}=$ $A \bar{K}_{t}^{\phi}\left(K_{t}^{i}\right)^{\alpha}\left(L_{t}^{i}\right)^{1-\alpha}$ where $i$ indexes a firm among a continuum of unit measure, and $\bar{K}$ denotes the average of all $K^{i}$ s. Firms in the economy are competitive and factors are paid their marginal product. Let $w$ denote the wage and $q$ denote the gross interest rate. Assuming firms are identical, $L_{t}^{i}=1$, and $\phi=1-\alpha$, output at date $t$ (expressed in intensive form) is $y_{t}=A k_{t}$, and

$$
\begin{aligned}
& w_{t}=(1-\alpha) A k_{t} \\
& q_{t}=\alpha A .
\end{aligned}
$$

For future reference, define the (gross) growth rate between dates $t$ and $t+1$ as $\gamma_{t} \equiv$ $y_{t+1} / y_{t}=k_{t+1} / k_{t}$.

An agent born at $t$ chooses consumption when young (old) $c_{t},\left(x_{t}\right)$, saves $s_{t}$, and possibly, leaves a bequest, $b_{t}$. Let $\Omega_{t}$ denote a vector of the economy-wide state variables facing a young agent born at date $t$. $\Omega_{t}$ includes, along with factor prices, consumption floors $\theta_{t}$ $\left(\delta_{t}\right)$ that the agent faces when young (old); $\Omega_{t} \equiv\left(w_{t} ; q_{t} ; \theta_{t} ; \delta_{t}\right)$. Given her inheritance, $b_{t-1}$, the agent solves the following problem: choose $c_{t}, x_{t}, s_{t}, b_{t}$ to:

$$
V\left(\Omega_{t} ; b_{t-1}\right) \equiv \max \left[u\left(c_{t} ; \theta_{t}\right)+\beta u\left(x_{t} ; \delta_{t}\right)+\lambda \beta V\left(\Omega_{t+1} ; b_{t}\right)\right]
$$

subject to:

$$
\begin{aligned}
& \text { c-1 } c_{t}+s_{t} \leq w_{t}+b_{t-1} \\
& \mathbf{c - 2} \quad x_{t}+b_{t} \leq q_{t} s_{t} \\
& \mathbf{c - 3} \quad c_{t} \geq \theta_{t} ; \quad x_{t} \geq \delta_{t} . \\
& \mathbf{c - 4} \quad s_{t} \geq 0 ; \quad b_{t} \geq 0 .
\end{aligned}
$$


The parameter $1>\lambda \geq 0$ captures the weight of the child's utility relative to the parent's; this form, with $\lambda<1$ is known as 'impure altruism'. ${ }^{7} \beta>0$ is a parameter. ${ }^{8}$

Following Barnett and Bhattacharya (2008) and Alonso-Carrera et. al. (2008), the consumption floors $\theta$ and $\delta$ are defined as follows:

$$
\theta_{t} \equiv\left(\theta_{y} \bar{c}_{t}+\theta_{o} \bar{x}_{t-1}\right) ; \delta_{t} \equiv\left(\delta_{y} \bar{c}_{t+1}+\delta_{o} \bar{x}_{t}\right)
$$

Here, variables with "bars" represent average levels of consumption, taken as parametric by the agent. For example, $\bar{c}_{t}$ represents the average level of consumption of the agent's generational cohorts when she is young. In equilibrium, $c_{t}=\bar{c}_{t}$ and $x_{t}=\bar{x}_{t}$ will hold. $\theta_{y}$ and $\theta_{o}$ represent scalars capturing the strength of the influence of the current youth and current old's consumption, respectively, on the young. ${ }^{9}$ Similarly, scalars $\delta_{y}$ and $\delta_{o}$ capture the strength of the influence of the current youth and current old's consumption, respectively, on the consumption of the agent when old. This formulation allows a generation other than one's own to influence the agent's consumption decision. Such intra- and intergenerational consumption externalities feature prominently in Abel (2005) and Alonso-Carrera et. al. (2008). Specifically, Barnett and Bhattacharya (2008) associate $\delta_{y}>0$ with "rejuvenile" behavior: the current old trying to keep up with the current young. Sociologists and other social scientists have noted the increasing influence of youth-culture and tastes on other members of society. See Noxon (2006) for a casual but enlightening discussion.

Of critical importance is the non-negativity constraint on bequests in c-4 above. The literature studying models with dynastic preferences and bequests has only analyzed steady states in which this constraint either binds or it does not. The present model allows us to consider the out-of-steady state possibility that the constraint may bind occasionally and examine the associated dynamic consequences.

\footnotetext{
${ }^{7}$ These are the exact preferences used, for example, in Phelps and Pollak (1968) and Aiyagari, Greenwood, and Sheshadri (2002).

${ }^{8}$ As is well known, it is not necessary to interpret $\beta$ as a discount factor in two-period overlappinggeneration models. Indeed, $\beta$ may be defined as innate relative preference for old-age consumption. All our results below go through even if $\beta=1$.

${ }^{9}$ This is reminiscent of the notion of "keeping up with the ageing Joneses" in Fisher and Heijdra (2009).
} 
Given an initial stock of capital, $k_{1}$, an initial old agent at date 1 chooses $x_{0}, b_{0}$ to maximize $u\left(x_{0} ; \delta_{1}\right)+\lambda \beta V\left(\Omega_{1} ; b_{0}\right)$ subject to $x_{0}+b_{0} \leq \alpha A k_{1}$. For future reference, note that while $k_{1}>0$ is given, $\gamma_{1}$, the initial growth rate, is not.

At each date, the following market-clearing conditions must hold:

Goods $c_{t}+x_{t-1}+k_{t+1}=y_{t}$

Capital $s_{t}=k_{t+1}$

Labor $L_{t}=1$.

Given $k_{1}$, an equilibrium for this economy is a sequence of consumption allocations $\left\{c_{t}, x_{t}\right\}_{t=1}^{\infty}$ and $x_{0}$; allocations of saving, capital, and bequests, $\left\{s_{t} ; k_{t} ; b_{t-1}\right\}_{t=1}^{\infty}$, and factor prices $\left\{w_{t} ; q_{t}\right\}_{t=1}^{\infty}$ that solve the agents' optimization problem at each date, satisfy the market-clearing conditions, and the factor prices satisfy (1)-(2). Additionally, if the bequest motive is operative at each date, i.e., $b_{t}>0 \forall t$, the sequence of bequests must satisfy a transversality condition:

$$
\lim _{t \rightarrow \infty}(\lambda \beta)^{t} u_{1}\left(c_{t} ; \theta_{t}\right) b_{t-1}=0
$$

For the remainder of the paper, we assume agents have preferences represented by the felicity functions

$$
u(a ; \psi)=\frac{(a-\psi)^{1-\sigma}}{1-\sigma}
$$

for $a=c_{t}, x_{t}, \psi=\theta_{t}, \delta_{t}$, where $\sigma>0, \theta_{t} \geq 0$, and $\delta_{t} \geq 0$, for $t \geq 1$.

\section{The benchmark economy with no consumption externali- ties}

A useful benchmark to study is the special case of no consumption externalities of any kind. A version of this, for a concave neoclassical production technology, has been studied by 
Michel et. al (2006). To the best of our knowledge, ours is a first attempt at characterizing stationary and non-stationary equilibria in the textbook $A k$ model with bequests. ${ }^{10}$

\subsection{Equilibrium allocations}

Set $\delta_{y}=\delta_{o}=\theta_{y}=\theta_{o}=0$. In this case, the first order conditions can be written as

$$
x_{t}=z c_{t}
$$

and

$$
x_{t}^{-\sigma} \geq \lambda c_{t+1}^{-\sigma} \quad\left(=\text { if } b_{t}>0\right) .
$$

where $z \equiv(\beta \alpha A)^{1 / \sigma}$. In an equilibrium with $b_{t}>0 \forall t>1$, the bequest and consumption allocations must also satisfy a transversality condition:

$$
\lim _{t \rightarrow \infty}(\lambda \beta)^{t} u^{\prime}\left(c_{t}\right) b_{t-1}=0
$$

The first condition (5) is standard. The second condition (6) states that for an old agent, the marginal cost of a bequest (in utility terms) is at least as great as its marginal benefit, as measured by the parent. Since a bequest is passed along to the child as a lump-sum income transfer, it does not alter the marginal conditions, summarized by (5) for $t+1$, that determine the child's optimal mix of young and old age consumption. Time separability of the utility function explains why the impact of additional resources from mother to child is captured solely by the marginal effect of these resources only on the child's young-age utility, $\lambda u^{\prime}\left(c_{t+1}\right)$.

A quick look at the consumption corner solution is in order. Consider a parent who does not consume $\left(x_{t}=0\right)$ and bequeaths her entire old-age capital income $\left(\alpha A k_{t}\right)$; additionally her child does not consume $\left(c_{t}=0\right)$ and saves her entire wage income $(1-\alpha) A k_{t}$. Using the market-clearing conditions, we get $k_{t+1}=A k_{t}$, and hence, in this case, the growth rate

\footnotetext{
${ }^{10}$ Caballe (1995) analyzes steady-state equilibria with positive and zero bequests in an endogenous growth model, with human capital as the engine of growth.
} 
between $t-1$ and $t$ is $\gamma_{t}=A$. This is the maximum feasible growth rate in this economy. Notice this upper bound is the same for a corresponding economy with consumption externalities ( since $c_{t}=x_{t}=0$ imply $\theta_{t}=\delta_{t}=0$ ). However, given the preferences in (4) with $\psi=0$, it is clear that $\lim _{m \rightarrow 0} u^{\prime}(m)=\infty, m=c_{t}, x_{t}$ holds, implying, for positive incomes, the corner $c_{t}=x_{t}=0$ is never chosen, and hence, $\gamma_{t}=A$ cannot be an equilibrium growth rate. Henceforth, we restrict $\gamma_{t} \in[0, A)$.

Given $b_{t-1}$, we use (6) with equality, along with the budget constraint (c-1) and the market-clearing conditions to solve for the agent's consumption $x_{t}$ and bequest $b_{t}$ decisions. We write these in terms of the growth rate $\gamma_{t}$ and the date $t$ capital stock:

$$
\begin{aligned}
& b_{t}=\left\{\begin{array}{cc}
0 & \text { if } \gamma_{t+1} \leq \gamma_{b m} \\
\frac{\left(\gamma_{t+1}-\gamma_{b m}\right) \gamma_{t} k_{t}}{1+\lambda^{1 / \sigma}} & \text { if } \gamma_{b m}<\gamma_{t+1}<A
\end{array}\right. \\
& x_{t}=\left\{\begin{array}{cc}
\alpha A \gamma_{t} k_{t} & \text { if } b_{t}=0 \text { i.e., if } \gamma_{t+1} \leq \gamma_{b m} \\
\frac{\left(A-\gamma_{t+1}\right) \gamma_{t} k_{t}}{1+\lambda^{1 / \sigma}} & \text { if } b_{t}>0 \text { i.e., if } \gamma_{b m}<\gamma_{t+1}<A
\end{array}\right.
\end{aligned}
$$

and

$$
c_{t}=\left\{\begin{array}{cl}
\left((1-\alpha) A-\gamma_{t}\right) k_{t} & \text { if } \gamma_{t} \leq \gamma_{b m} \\
\frac{\lambda^{1 / \sigma}\left(A-\gamma_{t}\right) k_{t}}{1+\lambda^{1 / \sigma}} & \text { if } \gamma_{t}>\gamma_{b m}
\end{array}\right.
$$

where

$$
\gamma_{b m} \equiv A\left((1-\alpha)-\alpha \lambda^{1 / \sigma}\right)
$$

(the subscript " $b m$ " stands for benchmark model). The consumption decision of an initial old agent, $x_{0}$, is similar to the expression for $x_{t}$ above, with $k_{1}$ replacing $\gamma_{t} k_{t}$ everywhere, and $\gamma_{t+1}=\gamma_{1}$.

Among the first things to note is that while the size of $c_{t}$ depends on the current growth rate, the size of old-age consumption $x_{t}$ depends on the future growth rate. From the expression for $b_{t}$, it is clear that the decision of the old at date $t$ of whether or not to pass along a bequest depends critically on the prospective growth rate. Specifically, a 
positive bequest is made if and only if the future growth rate $\gamma_{t+1}$, exceeds $\gamma_{b m}$. In this connection, note that higher values of $\lambda$ make it easier for the future growth rate to exceed $\gamma_{b m}$. Next, note that $c_{t} \geq 0$ holds whenever $0<\gamma_{t} \leq \gamma_{b m}$, since $\left((1-\alpha) A-\gamma_{t}\right) k_{t} \geq$ $\left((1-\alpha) A-\gamma_{b m}\right) k_{t}=\alpha \lambda^{1 / \sigma} k_{t}$ for all $\gamma_{t} \leq \gamma_{b m}$. When $\gamma_{t}>\gamma_{b m}$, for $c_{t} \geq 0$, we need $\gamma_{t}<A$. Finally, if $\gamma_{b m}<0$, the only possible equilibria will be those with positive bequests.

Why are bequests dependent on a threshold value of the future growth rate? A sufficiently high growth rate between dates $t+1$ and $t+2$ requires a high level of saving by the child at $t+1$, thereby raising the child's marginal utility of young-age consumption (which, as discussed above, also raises the marginal benefit of the parent's bequest gift). This is weighed against the marginal cost of the gift - the parent's marginal loss in utility due to lowered consumption when old. The threshold growth rate $\gamma_{b m}$, then, represents a rate of future growth such that the marginal cost of a bequest equals the marginal benefit of a bequest, both evaluated at $b_{t}=0$.

In passing, it should be pointed out that the expressions for optimal consumptions and bequests are more tractable than what one gets in an otherwise-identical model with a concave, neoclassical technology (such as, the one studied in Thibault, 2000 and Michel et. al, 2006). This permits an easier characterization of the operativeness of the bequest motive; in particular, it allows a full-blown dynamic analysis.

\subsection{Dynamics of the growth rate and the pattern of bequests}

Using (5) along with the solutions for the consumption allocations $x$ and $c$ derived in Section 3.1 , one obtains a dynamic linkage connecting the growth rate at date $t$ with that at date $t+1$ - a first-order difference equation in the growth rate, $\gamma_{t}$. Given some $\gamma_{t} \in[0, A)$, a momentary equilibrium at date $t+1$ for this economy is a growth rate $\gamma_{t+1} \in[0, A)$ that satisfies this difference equation. We define a momentary bequest equilibrium at date $t+1$ as a momentary equilibrium that additionally satisfies $b_{t}>0$. A momentary no-bequest 
equilibrium at date $t+1$ is a momentary equilibrium that satisfies $b_{t}=0$. For future use, we make the following parametric assumption:

\section{Assumption $1 \quad \lambda<(A / z)^{\sigma}$}

A dynamically-valid equilibrium law of motion for this economy is an infinite sequence of momentary equilibrium points, $\left\{\gamma_{t}\right\}_{t=1}^{\infty}$, which satisfies this difference equation, Assumption 1 , and $\gamma_{t} \in[0, A) \forall t$.

In this setting, there isn't a unique expression for the equilibrium law of motion for the

growth rate. This is because at any date, $\gamma_{t} \lesseqgtr \gamma_{b m}$ and $\gamma_{t+1} \lesseqgtr \gamma_{b m}$ are possible, which in turn affects the decision to leave bequests at that date. In other words, knowing $\gamma_{t}$, one knows whether the current young received an inheritance from their parents, but not whether they, in due course, would leave a bequest. Four cases need to be analyzed: one where the current young neither received an inheritance nor did they leave a bequest (case A), one where the current young did not receive an inheritance yet left a bequest (case $\mathbf{B}$ ), one where the current young received an inheritance and did not leave a bequest (case $\mathbf{C})$, and one where the current young received an inheritance and left a bequest (case $\mathbf{D}$ ). These four possibilities translate into four candidate pieces of the equilibrium law of motion for the growth rate:

$$
z=\frac{x_{t}}{c_{t}}=\left\{\begin{array}{ccc}
\frac{\alpha A \gamma_{t}}{\left((1-\alpha) A-\gamma_{t}\right)} & \text { if } \gamma_{t} \leq \gamma_{b m} \wedge \gamma_{t+1} \leq \gamma_{b m} & \text { case } \mathbf{A} \\
\frac{\left(A-\gamma_{t+1}\right) \gamma_{t}}{\left(1+\lambda^{1 / \sigma}\right)\left((1-\alpha) A-\gamma_{t}\right)} & \text { if } \gamma_{t} \leq \gamma_{b m} \leq \gamma_{t+1} & \text { case } \mathbf{B} \\
\frac{\left(1+\lambda^{1 / \sigma}\right) \alpha A \gamma_{t}}{\lambda^{1 / \sigma}\left(A-\gamma_{t}\right)} & \text { if } \gamma_{t+1} \leq \gamma_{b m} \leq \gamma_{t} & \text { case } \mathbf{C} \\
\frac{\left(A-\gamma_{t+1}\right) \gamma_{t}}{\lambda^{1 / \sigma}\left(A-\gamma_{t}\right)} & \text { if } \gamma_{b m} \leq \gamma_{t} \wedge \gamma_{b m} \leq \gamma_{t+1} & \text { case } \mathbf{D}
\end{array}\right.
$$

In appendix A, we show that the only possible momentary equilibria are those involving either case A or case D but not both. In the former case, Ricardian equivalence does not hold; it does in the latter case.

Proposition 1 a) Suppose the parametric condition, $\lambda<\left(\gamma_{b m} / z\right)^{\sigma}$, holds, where $\gamma_{b m}$ is defined in (8); then no bequests are granted at any date and $\gamma_{t}=\frac{A z(1-\alpha)}{z+\alpha A} \in(0, A)$ for $t \geq 1$. 
b) If $(A / z)^{\sigma}>\lambda>\left(\gamma_{b m} / z\right)^{\sigma}$, bequests are granted at each date, and $\gamma_{t}=z \lambda^{\frac{1}{\sigma}}$ for $t \geq 1$. The steady state is locally unstable.

c) If $\lambda \geq(A / z)^{\sigma}$, i.e., if Assumption 1 is violated, no equilibria exist.

If the weight of the child's utility in the parent's utility is sufficiently low, no bequests are passed on at any date, and the growth rate for such a economy is forever constant. If the weight is high enough (but not too high), then bequests are passed on at every date, and the growth rate for such a economy is also, forever constant. ${ }^{11}$

A few words about Proposition 1 are in order. These mutually-exclusive conditions on $\lambda$ preclude the co-existence of momentary bequest equilibria alongside momentary nobequest equilibria. The proposition further ensures that only a stationary equilibrium obtains. Consequently, depending on $\lambda$, the economy is either, instantly at a steady state in which the bequest motive is operative at each date, or it is not. There is no indeterminacy of any kind; given $\lambda$, the equilibrium is unique. ${ }^{12}$

Why can't the benchmark model economy support momentary equilibria where the non-negativity constraint on bequests binds occasionally? To understand the intuition, it suffices to understand, for example, why a old person never leaves a bequest if she did not receive an inheritance when young. The logic is somewhat like this. If a young agent, Ms. $\mathrm{X}$, does not receive an inheritance at date $t$, it must be because her mother anticipates (correctly) that her daughter will not save much of her wage (and potential) inheritance income, which is precisely why the growth rate $\gamma_{t}$, is low, triggering a no-bequest given response from the parent. Lacking an inheritance, Ms. $\mathrm{X}$ is unable to save enough to leave

\footnotetext{
${ }^{11}$ In the benchmark model, there may be a deviant generation at the initial date in a trivial sense. This may happen, if for example, the initial old leave a bequest but no other generation does.

${ }^{12}$ Each momentary equilibrium $\gamma_{t+1}$ is indexed by the growth rate that precedes it, $\gamma_{t}$. This means that any sequence of momentary equilibria will be indexed by $\gamma_{1}$. Generally, this would imply the resulting sequence is indeterminate - the indeterminacy stemming from the fact that $\gamma_{1}$ is arbitrarily chosen. However, in this case, the limiting conditions for the sequence impose enough additional restrictions to pin down the initial value $\gamma_{1}$. In other words, the only values of $\gamma_{1}$ that ensure a bona fide equilibrium obtains will be $A z(1-\alpha)(/ z+\alpha A)$ or $z \lambda^{\frac{1}{\sigma}}$ (depending on the size of the parameter $\lambda$ in relationship to $\left.[(1-\alpha) A /(\alpha A+z)]^{\sigma}\right)$.
} 
a bequest of her own at date $t+1$. On the other hand, if the mother leaves a bequest to her child, the child is able to save enough to pass along a bequest herself, and sufficiently high saving at $t$ ensures the growth rate $\gamma_{t}>\gamma_{b m}$. Bequests bestow on the child the ability to save enough to leave a bequest. If the initial bequest at date $1, b_{0}$, is large enough, enabling Generation 1 to save enough to leave a bequest at date 2, all generations will have sufficient wage and inheritance income to pass along a bequest to their offspring.

\section{Intergenerational consumption externalities}

We turn next to a general setting in which intergenerational consumption externalities are present. As we will show, such intergenerational influences on consumption standards have the potential to introduce interesting dynamics in bequest giving. It is here that the possibility of deviant generations emerges.

\subsection{Equilibrium allocations}

Recall, a young agent's problem is to maximize (3) subject to constraints (c-1)-(c-4). It is easy to verify that analogous to (5) and (6), the first order conditions are summarized by

$$
x_{t}-\delta_{t}=z\left(c_{t}-\theta_{t}\right)
$$

(hereafter referred to as the "intragenerational optimality linkage") and

$$
\left(c_{t+1}-\theta_{t+1}\right) \geq \lambda^{1 / \sigma}\left(x_{t}-\delta_{t}\right) \quad\left(=\text { if } b_{t}>0\right),
$$

(hereafter, the "intergenerational optimality linkage").

Using (9)-(10), the optimal consumption and bequest choices are given by

$c_{t}-\theta_{t}=\left\{\begin{array}{cl}\left(\left(1-\theta_{y}\right)(1-\alpha) A-\alpha A \theta_{o}-\left(1-\theta_{y}\right) \gamma_{t}\right) k_{t} & \text { if } \gamma_{t} \leq \gamma_{c e} \\ \left(\left(1-\theta_{y}\right)\left((1-\alpha) A-\gamma_{t}\right)+\left(1-\theta_{y}+\theta_{o}\right)\left(\alpha A-\Lambda+\frac{\Lambda}{A} \gamma_{t}\right)-\theta_{o} \alpha A\right) k_{t} & \text { if } \gamma_{t}>\gamma_{c e}\end{array}\right.$ 
$x_{t}-\delta_{t}=\left\{\begin{array}{cc}\left(\left(1-\delta_{o}\right) \alpha A-\delta_{y}(1-\alpha) A+\delta_{y} \gamma_{t+1}\right) \gamma_{t} k_{t} & \text { if } A_{1} \leq \gamma_{t+1} \leq \gamma_{c e} \\ \left(\Lambda\left(1-\delta_{o}+\delta_{y}\right)-\delta_{y} A-\left(\frac{\Lambda}{A}\left(1-\delta_{o}+\delta_{y}\right)-\delta_{y}\right) \gamma_{t+1}\right) \gamma_{t} k_{t} & \text { if } \gamma_{t+1}>\gamma_{c e}\end{array}\right.$

and

$$
b_{t}=\left\{\begin{array}{cl}
0 & \text { if } \gamma_{t+1} \leq \gamma_{c e} \\
\left(\alpha A-\Lambda\left(1-\frac{\gamma_{t+1}}{A}\right)\right) \gamma_{t} k_{t} & \text { if } \gamma_{t+1}>\gamma_{c e}
\end{array}\right.
$$

where

$$
A_{1} \equiv \frac{\delta_{y}(1-\alpha) A-\left(1-\delta_{o}\right) \alpha A}{\delta_{y}} ; \quad \Lambda \equiv \frac{\left(1-\theta_{y}+\lambda^{1 / \sigma} \delta_{y}\right) A}{\lambda^{1 / \sigma}\left(1-\delta_{o}+\delta_{y}\right)+\left(1-\theta_{y}+\theta_{o}\right)},
$$

and the cut-off growth rate is given by

$$
\gamma_{c e} \equiv A(1-\alpha)-\frac{\alpha A\left(\theta_{o}+\lambda^{\frac{1}{\sigma}}\left(1-\delta_{o}\right)\right)}{1-\theta_{y}+\lambda^{\frac{1}{\sigma}} \delta_{y}}
$$

(the subscript "ce" stands for consumption externalities). Below we show that $\gamma_{t+1} \geq A_{1}$ always holds. If

$$
\left(1-\delta_{o}\right) \alpha<\delta_{y}(1-\alpha)
$$

holds, then $A_{1}>0$.

To ensure (c-3) is satisfied, we make the following parametric assumptions.

Assumption $2(1-\alpha)\left(1-\theta_{y}\right)-\alpha \theta_{o}-\alpha \lambda^{\frac{1}{\sigma}}\left(1-\delta_{o}+\delta_{y}\right)+\lambda^{\frac{1}{\sigma}} \delta_{y}>0$

Assumption $3\left(1-\delta_{o}\right)\left(1-\theta_{y}\right)>\theta_{o} \delta_{y}$

It is easily verified that Assumptions 2-3 are necessary for $c_{t}>\theta_{t}$ and $x_{t}>\delta_{t}$ to hold.

As before, we can, mutatis mutandis, construct a first-order difference equation (using (9)) in $\gamma_{t}$ that links the growth rate at date $t$ with that at date $t+1$. The definitions of momentary equilibrium, momentary bequest equilibrium, and dynamically-valid equilibrium sequence, provided in the previous section, apply here as well. 
With the knowledge of the equilibrium allocations in hand, we now proceed to characterize the time path of the growth rate. To presage, for a range of the altruism factor, $\lambda$, one can construct dynamically-valid equilibrium sequences in which the bequest motive is operative at every date - here Ricardian equivalence holds. For $\lambda$ outside of this range, momentary equilibria characterized by the non-negativity constraint on bequests binding occasionally become possible. In this case, any equilibrium with bequests must display intergenerational differences in bequest-giving behavior along both intensive and extensive margins.

\subsection{Dynamic linkages}

We now investigate dynamic configurations represented by (9). To foreshadow, we will find that equilibria and dynamics are crucially connected to the size of $\lambda$, specifically whether $\lambda \gtreqless\left(\gamma_{c e} / z\right)^{\sigma}$.

A No-Bequest Equilibrium. We start by investigating momentary equilibria assuming the non-negativity constraint on bequests binds at each date. Here, the growth rate is forever below the threshold rate, $\gamma_{t} \leq \gamma_{c e}$ for $t \geq 1$. Each generation receives no inheritance, nor pass a bequest along, i.e., $b_{t}=0 \forall t \geq 1$. This corresponds to the configuration studied in Barnett and Bhattacharya (2008). The intragenerational optimality linkage in (9) may be rewritten as

$$
\frac{f\left(\gamma_{t+1}\right) \gamma_{t}}{g\left(\gamma_{t}\right)}=z
$$

where

$$
f\left(\gamma_{t+1}\right) \equiv\left(1-\delta_{o}\right) \alpha A-\delta_{y}(1-\alpha) A+\delta_{y} \gamma_{t+1}
$$

and

$$
g\left(\gamma_{t}\right) \equiv\left(1-\theta_{y}\right)(1-\alpha) A-\alpha A \theta_{o}-\left(1-\theta_{y}\right) \gamma_{t}
$$


The presence of the rejuvenile externality $\left(\delta_{y}>0\right)$ is critical here. In its absence, $f$ is independent of $\gamma$, and no dynamics in $\gamma$ is possible; the only equilibrium that obtains is one in which the initial growth rate selected equals the steady-state value, $A z\left[\frac{\left(1-\theta_{y}\right)(1-\alpha)-\alpha \theta_{o}}{\left(1-\delta_{o}\right) \alpha A+z\left(1-\theta_{y}\right)}\right]$. More generally, when $\delta_{y}>0$, we have

$$
\gamma_{t+1}=A_{1}+A_{2} \frac{g\left(\gamma_{t}\right)}{\gamma_{t}}
$$

where $A_{2} \equiv z / \delta_{y}>0$. Eq. (18) describes all momentary equilibria with zero bequests. Using (18), it is easy to check that over this region, $\frac{\partial \gamma_{t+1}}{\partial \gamma_{t}}<0$ and $\frac{\partial^{2} \gamma_{t+1}}{\partial \gamma_{t}^{2}}>0$ holds; also, there exists a $\gamma_{\min }$ such that $\lim _{\gamma_{t} \rightarrow \gamma_{\min }} \gamma_{t+1}=\gamma_{c e}$. Since $\frac{\partial \gamma_{t+1}}{\partial \gamma_{t}}<0$, this implies the law of motion is not defined for values of $\gamma_{t}<\gamma_{\min }$.

Moreover,

$$
\lim _{\gamma_{t} \rightarrow \gamma_{c e}} \gamma_{t+1}=A_{1}+A_{2} \frac{g\left(\gamma_{c e}\right)}{\gamma_{c e}} \gtrless \gamma_{c e} \text { if } \lambda \gtrless\left(\gamma_{c e} / z\right)^{\sigma} \text {. }
$$

This, together with the fact that the law of motion is strictly decreasing, implies $\gamma_{t} \leq \gamma_{c e}$ for $t \geq 1$ cannot hold if $\lambda>\left(\gamma_{c e} / z\right)^{\sigma}$. In short, when $\lambda>\left(\gamma_{c e} / z\right)^{\sigma}$, there are no valid no-bequest equilibria in this SW quadrant of Figure 1. 


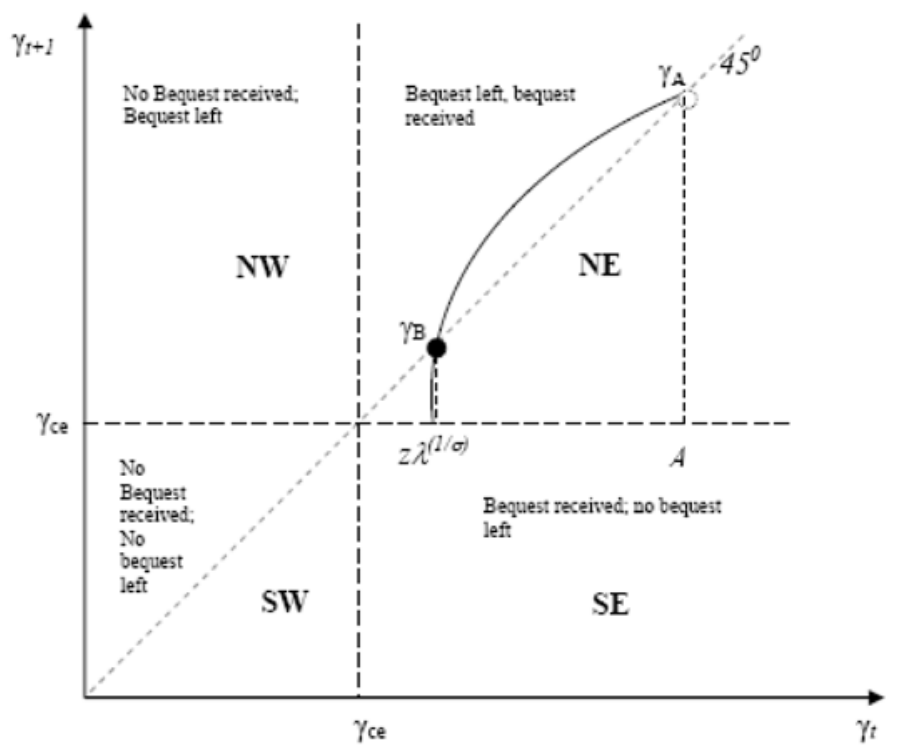

Figure 1: Dynamics of the growth rate when $\lambda>\left(\gamma_{c e} / z\right)^{\sigma}$

When $\lambda<\left(\gamma_{c e} / z\right)^{\sigma}, \lim _{\gamma_{t} \rightarrow \gamma_{c e}} \gamma_{t+1}<\gamma_{c e}$ holds. This, along with $\lim _{\gamma_{t} \rightarrow \gamma_{\min }} \gamma_{t+1}=\gamma_{c e}$ and $\frac{\partial \gamma_{t+1}}{\partial \gamma_{t}}<0$ implies (18) is as depicted in the SW quadrant in Figure 2 below. The existence and uniqueness of a steady state $\left(\gamma_{r e j}^{*}\right)$ in this quadrant is immediate. The steady state $\left(\gamma_{\text {rej }}^{*}\right)$ is locally stable iff ${ }^{13}$

$\frac{\partial \gamma_{t+1}}{\partial \gamma_{t} \gamma_{r e j}^{*}}>-1 \Leftrightarrow A \delta_{y}(1-\alpha)-A \alpha\left(1-\delta_{o}\right)>z\left(1-\theta_{y}\right)$.

A Bequest Equilibrium. We turn next to the study of momentary bequest equilibria by assuming the non-negativity constraint on bequests does not bind at any date. Here,

\footnotetext{
${ }^{13}$ This is the same condition as Assumption 3 in Barnett and Bhattacharya (2008). In this case, two (but no higher period) cycles are possible in a neighborhood of the steady state $\gamma_{r e j}^{*}$. To reiterate, these are cycles in the growth rate; along such cycles, the level of bequests will always be zero.
} 
$\gamma_{t}>\gamma_{c e}$ at each date so that Generation $t$ receives a inheritance and passes a bequest along. The appropriate intertemporal condition (9) may be reformulated as

$$
\frac{b\left(\gamma_{t+1}\right) \gamma_{t}}{g\left(\gamma_{t}\right)+h\left(\gamma_{t}\right)}=z
$$

where $g$ is defined in (17),

$$
b\left(\gamma_{t+1}\right) \equiv\left(\left(1-\delta_{o}+\delta_{y}\right) \Lambda-\delta_{y} A\right)\left(1-\frac{\gamma_{t+1}}{A}\right), \quad \forall \gamma_{t+1}>\gamma_{c e}
$$

and

$$
h\left(\gamma_{t}\right) \equiv\left(1-\theta_{y}+\theta_{o}\right)\left(\alpha A-\Lambda\left(1-\frac{\gamma_{t}}{A}\right)\right)
$$

is defined for $\gamma_{c e} \leq \gamma_{t}<A$. For future reference, note that (19) may be compactly written as

$$
\gamma_{t+1}=B_{1}+B_{2} \frac{g\left(\gamma_{t}\right)+h\left(\gamma_{t}\right)}{\gamma_{t}}
$$

where $B_{1} \equiv A$ and $B_{2} \equiv-A z /\left[\left(1-\delta_{o}+\delta_{y}\right) \Lambda-\delta_{y} A\right]<0$, and (20) reduces to a tractable first-order difference equation:

$$
\gamma_{t+1}=\frac{1}{\gamma_{t}}\left(A \gamma_{t}-A z \lambda^{\frac{1}{\sigma}}+z \lambda^{\frac{1}{\sigma}} \gamma_{t}\right)
$$

Clearly, $\gamma_{t+1}$ is an increasing and strictly concave function of $\gamma_{t}$.It is easy to check that (21) admits two steady states, $\gamma_{A}=A$ and $\gamma_{B}=z \lambda^{1 / \sigma}$, where Assumption 1 ensures that $\gamma_{A}>\gamma_{B}$. For reasons discussed earlier, the steady state, $\gamma_{A}$, is economically infeasible. Additionally, under Assumption 1,

$$
\left.\frac{\partial \gamma_{t+1}}{\partial \gamma_{t}}\right|_{\gamma=\gamma_{B}}=\frac{A}{z \lambda^{\frac{1}{\sigma}}}>1
$$

implying that $\gamma_{B}$ is locally unstable. Similarly, $\gamma_{A}$ is verified to be locally stable.

Finally, the location of $\gamma_{B}$ relative to the cut-off, $\gamma_{c e}$, remains to be checked. If $z \lambda^{1 / \sigma}>\gamma_{c e} \Leftrightarrow \lambda>\left(\gamma_{c e} / z\right)^{\sigma}$ holds (see Figure 1 ), then $\gamma_{B}$ is to the right of the cutoff, whereas if $\lambda<\left(\gamma_{c e} / z\right)^{\sigma}, \gamma_{B}$ is located to the left of the cut-off; in this case, there is no 
valid steady state (see Figure 2). These results are summarized in Proposition 2 below.

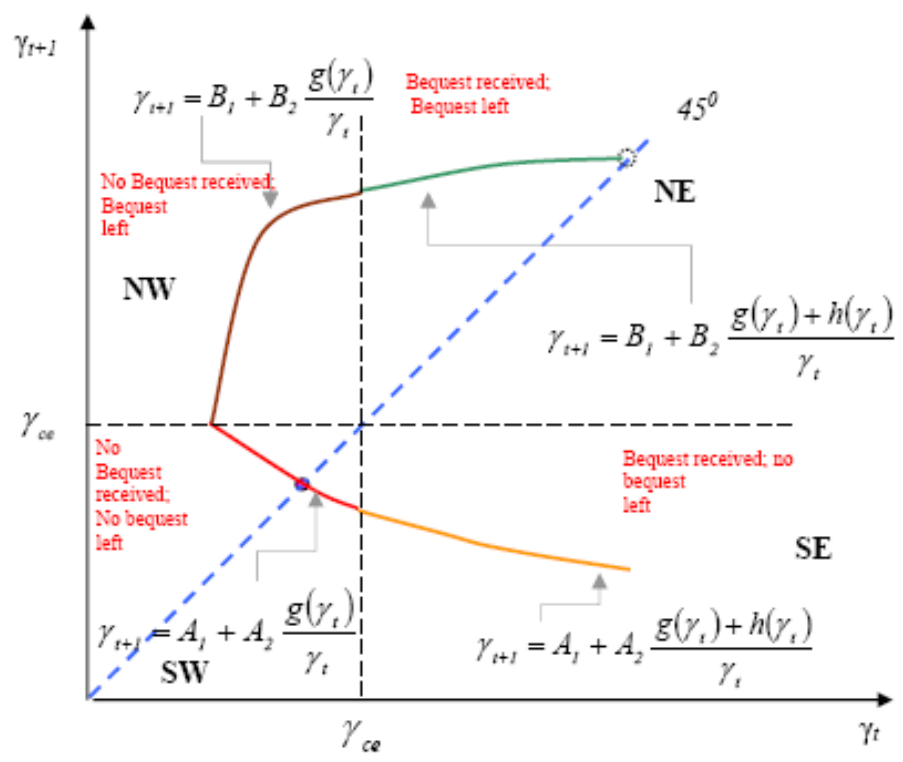

Figure 2: Dynamics of the growth rate when $\lambda<\left(\gamma_{c e} / z\right)^{\sigma}$

Proposition 2 a) Suppose $\lambda<\left(\gamma_{c e} / z\right)^{\sigma}$ holds. Then, there exist sequences of momentary bequest equilibria converging to $\gamma_{A}$, but $\gamma_{A}$ itself not a momentary equilibrium, and hence, these sequences themselves are not valid equilibrium paths.

b) Suppose $\lambda>\left(\gamma_{c e} / z\right)^{\sigma}$ holds. Then, there exists an unique equilibrium in which bequests are granted at each date, and $\gamma_{t}=z \lambda^{\frac{1}{\sigma}}$ for $t \geq 1$. This equilibrium, the steady state $\gamma_{B}$, is locally unstable.

A few remarks about Proposition 2, the analog of Proposition 1, are in order. First, if $\lambda>\left(\gamma_{c e} / z\right)^{\sigma}$ holds, there exists an equilibrium in which the bequest motive is operative at every date. This is depicted in the NE quadrant of Figure 1. By implication, this is an equilibrium in which Ricardian equivalence holds. Second, this equilibrium is stationary, 
with $\gamma_{t}=\gamma_{B}=z \lambda^{\frac{1}{\sigma}}$. Third, it is unique; there is a unique $\gamma_{1}$, namely, $\gamma_{1}=z \lambda^{\frac{1}{\sigma}}$, that places the economy at this equilibrium. Finally, it deserves mention here that the growth rate at this equilibrium is exactly the same as in the benchmark model. Of course, this does not imply that equilibrium allocations, $x, c$, and $b$, are the same across the two models.

When $\lambda<\left(\gamma_{c e} / z\right)^{\sigma}$ holds, $\gamma_{B}$ (i.e., $\left.z \lambda^{\frac{1}{\sigma}}\right)$ is to the left of the cut-off; hence, the requirement that $\gamma_{t}>\gamma_{c e}$ holds at each date is violated at $\gamma_{B}$. The only steady-state of (21) is $\gamma_{A}$, which, as noted, is an attracting but not economically-valid equilibrium point. Also note that the bequest motive is operative at each and every date along the trajectory depicted in the NE quadrant of Figure 2. The last two statements taken together imply the following. No equilibrium sequence of growth rates can forever travel along the trajectory shown in the NE quadrant of Figure 2; at some date, it has to leave this quadrant, and when it does, the bequest motive will cease to operative. As a result, Ricardian equivalance will not hold. Note that this is in sharp contrast to what transpires in the benchmark model where either bequests are left and received by each and every generation or they are not for any generation.

Before closing this section, we ask, is it possible that the bequest motive is non-operative in the benchmark model but is operative in the model with consumption externalities? In other words, can Ricardian equivalence fail to obtain in the benchmark economy and yet hold in the corresponding model with consumption externalities?

Proposition 3 The bequest motive is operative in the model with consumption externalities, but not for the benchmark model if and only if

$$
\left(\gamma_{c e}\right)^{\sigma}<\beta<\left(\gamma_{b m}\right)^{\sigma}
$$

holds. $.^{14}, 15$

\footnotetext{
${ }^{14}$ An example of a parameter set that satisfies all previous parametric assumptions as well as (22) is: $\lambda=0.49, A=1.87, \beta=0.74, \alpha=0.28, \theta_{y}=0.44, \theta_{o}=0.71, \delta_{y}=0.08, \delta_{o}=0.81$, and $\sigma=1.74$.

${ }^{15}$ In the benchmark model, Ricardian equivalence does not obtain if $\lambda<\left(\frac{\gamma_{b m}}{z}\right)^{\sigma} \Leftrightarrow \beta<\frac{\left(\gamma_{b m}\right)^{\sigma}}{\alpha \lambda A}$.
} 
Under the condition listed in Proposition 3 (or under other equivalent parametric conditions), the presence of consumption externalities may have the potential to "jump start" bequest-giving, with concomitant implications for Ricardian equivalence.

\subsection{Deviant intergenerational linkages}

In addition to describing the equilibrium growth paths for economies where the nonnegativity constraint on bequests either binds or does not bind at each date, eqs. (18) and 20) also describe the relationship between consumption allocations between any two consecutive dates assuming the current generation chooses the same course of action - as it applies to bequests - as their parents. However, a priori there is no reason to believe that an economy cannot support alternative equilibrium paths, ones where any one particular generation does not leave a bequest even though their predecessors did, nor do their progeny feel they must follow in the same footsteps (bequest-wise) as their parents. These, as mentioned in Section 1, we refer to as deviant generations; their actions depart from those of their parents.

In addition to (18) and (20), the following can be used to describe the relation between the growth rates of any two consecutive dates. We characterize these based on whether or not a bequest is received and given.

No Inheritance Received, Bequest Given. If $\gamma_{t} \leq \gamma_{c e}$ and $\gamma_{t+1}>\gamma_{c e}$, Generation $t$ will leave a bequest to Generation $t+1$ even though Generation $t-1$ leaves no bequests for $t$. Trivially, no steady state can exist in this quadrant since $\gamma_{t} \leq \gamma_{c e}$ and $\gamma_{t+1}>\gamma_{c e}$ both have to hold. The intertemporal condition (9) is written as

$$
\frac{b\left(\gamma_{t+1}\right) \gamma_{t}}{g\left(\gamma_{t}\right)}=z
$$

If Ricardian equivalence is to obtain in the corresponding model with externalities,

$$
\lambda>\left(\frac{\gamma_{c e}}{z}\right)^{\sigma} \Leftrightarrow \beta>\frac{\left(\gamma_{c e}\right)^{\sigma}}{\alpha \lambda A}
$$

must hold. From here, (22) follows. Parametric conditions, equivalent to (22), are also easy to formulate. 
It is possible to rewrite this in a form analogous to (18) and (20)

$$
\gamma_{t+1}=B_{1}+B_{2} \frac{g\left(\gamma_{t}\right)}{\gamma_{t}}
$$

Eq.(23) describes all momentary equilibria of this type. Over this region, $\frac{\partial \gamma_{t+1}}{\partial \gamma_{t}}>0$ and $\frac{\partial^{2} \gamma_{t+1}}{\partial \gamma_{t}^{2}}<0$ holds. The maximum value for $\gamma_{t+1}$ in this case occurs when $\gamma_{t}=\gamma_{c e}$. It is easy to show that

$$
\lim _{\gamma_{t} \rightarrow \gamma_{c e}} \gamma_{t+1}=B_{1}+B_{2} \frac{g\left(\gamma_{c e}\right)}{\gamma_{c e}}<\gamma_{c e} \text { if } \lambda>\left(\gamma_{c e} / z\right)^{\sigma} .
$$

This, together with the fact that the law of motion is strictly increasing, implies $\gamma_{t} \leq \gamma_{c e}$ and $\gamma_{t+1}>\gamma_{c e}$ cannot hold; hence, there are no valid equilibria in the NW quadrant of Figure 1 if $\lambda>\left(\gamma_{c e} / z\right)^{\sigma}$.

When $\lambda<\left(\gamma_{c e} / z\right)^{\sigma}$, the law of motion is as is depicted in the NW quadrant of Figure 2. Note

$$
B_{1}+B_{2} \frac{g\left(\gamma_{\min }\right)}{\gamma_{\min }}=\gamma_{c e}
$$

implying that as we move from quadrant SW to quadrant NW, the law of motion is continuous. Similarly, since $h\left(\gamma_{c e}\right)=0$, the law of motion is continuous between quadrants NE and NW, but it is not differentiable at $\gamma_{c e}$, the separation between the quadrants.

Of course, there can be no dynamically-valid equilibrium sequence with two consequentially dates spent in this quadrant because if $\gamma_{t} \leq \gamma_{c e}$, no inheritance is received at date $t$ and yet since $\gamma_{t+1}>\gamma_{c e}$, Generation $t+1$ leaves a bequest (which means Generation $t+2$ receives an inheritance, which does not happen in quadrant NW).

Inheritance Received, No Bequest Given. If $\gamma_{t}>\gamma_{c e}$ and $\gamma_{t+1} \leq \gamma_{c e}$, the current growth rate is above the threshold rate $\gamma_{c e}$ needed to generate a bequest given to Generation $t$ from Generation $t-1$, though Generation $t$ leaves no bequests. This corresponds to the SE quadrant in Figures 1 and 2. Here, the intertemporal condition (9) is rewritten as

$$
\frac{f\left(\gamma_{t+1}\right) \gamma_{t}}{g\left(\gamma_{t}\right)+h\left(\gamma_{t}\right)}=z \text {. }
$$


As before, this may be reformulated as

$$
\gamma_{t+1}=A_{1}+A_{2} \frac{g\left(\gamma_{t}\right)+h\left(\gamma_{t}\right)}{\gamma_{t}}
$$

with $\frac{\partial \gamma_{t+1}}{\partial \gamma_{t}}<0$ and $\frac{\partial^{2} \gamma_{t+1}}{\partial \gamma_{t}^{2}}>0$ over this interval. Eq.(24) describes all momentary equilibria of this type. First, consider the setting in which $\lambda>\left(\gamma_{c e} / z\right)^{\sigma}$. It is immediately obvious that, in this case, (24) cannot represent an equilibrium sequence. After all, in the SE quadrant of Figure 1, bequests are received but not left, which implies the next point in the sequence has to involve either quadrants NW or SW, both of which are empty of valid equilibrium points.

When $\lambda<\left(\gamma_{c e} / z\right)^{\sigma}$, the law of motion in (24), as depicted in Figure 2, is continuous between quadrants SW and NW, but it is not differentiable at $\gamma_{c e}$. Note that

$$
\lim _{\gamma_{t} \rightarrow A} \gamma_{t+1}=A_{1}
$$

Since $\frac{\partial \gamma_{t+1}}{\partial \gamma_{t}}<0$, this implies $\gamma_{t+1}>A_{1} \forall t$. As in the NW quadrant, for reasons analogous to those outlined above, there is no valid dynamically-valid equilibrium sequence with two consecutive dates in this quadrant. In this sense, the 'law of motion' in the NE and SW quadrants is nothing more a loci of momentary equilibrium points.

\section{Bequest dynamics and growth cycles}

Our results thus far indicate that when $\lambda>\left(\gamma_{c e} / z\right)^{\sigma}$, there is a unique equilibrium (see Figure 1), one in which bequests are left and received each period. Here, Ricardian equivalence obtains. However, when $\lambda<\left(\gamma_{c e} / z\right)^{\sigma}$, there is no dynamically-valid equilibrium sequence in which bequests are left every period. The non-negativity constraint on bequests binds at some dates, and Ricardian equivalence fails. Interestingly though, a dynamically-valid sequence of momentary equilibria that supports bequest-giving, at least some of the time, may exist. 
One example of a dynamically-valid sequence of momentary equilibria, in which the non-negativity constraint on bequests binds occasionally, involves two branches of the law of motion (9)-(10) depicted in quadrants NW and SE of Figure 3. In such an example, the current generation would leave a bequest but their children wouldn't, but their children would, and so on - a simple example of generational bequest 2-cycles. These bequest cycles are a consequence of 2 -cycles in the growth rate. ${ }^{16}$

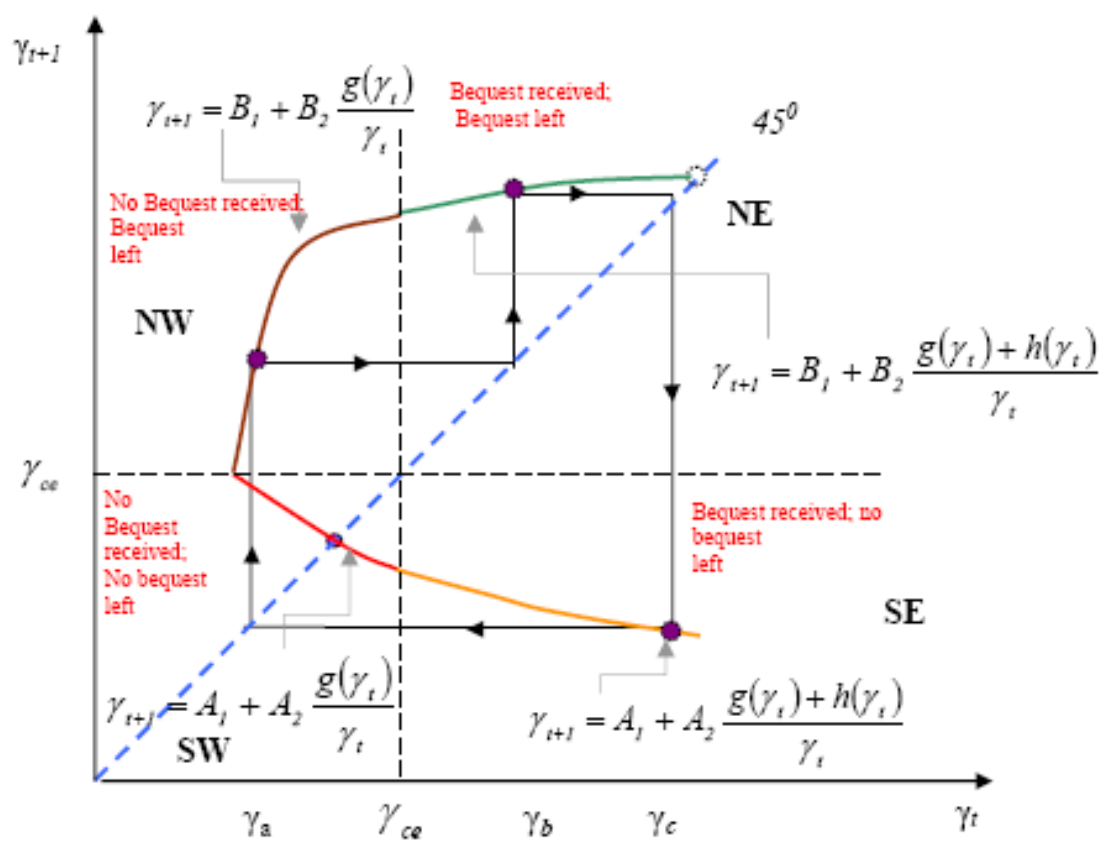

Figure 3: A 3-period limit cycle in the growth rate when $\lambda<\left(\gamma_{c e} / z\right)^{\sigma}$.

An alternative cyclical path is illustrated in Figure 3. In this configuration, the time path for the equilibrium growth rate forever travels from $\gamma_{a}$ to $\gamma_{b}$ to $\gamma_{c}$ and back to $\gamma_{a}$. This constitutes a three-period limit cycle successively involving quadrant NW (no inheritance received but bequest left), quadrant $\mathrm{NE}$ (inheritance received and bequest

\footnotetext{
${ }^{16}$ Similar, higher-order cycles (such as, a 4-period cycle) may also emerge between these two quadrants.
} 
left) and quadrant SE (inheritance received but no bequest left) onto quadrant NW (no inheritance received but bequest left). In common parlance, Generation $t$ is a generous, deviant generation (it received no inheritance but left a bequest), followed by Generation $t+1$ (a generation that acts in a manner consistent with their parent's actions), with Generation $t+2$ the deviant, stingy one (it received inheritances but left no bequests), followed by a new generous Generation $t+3$, and so forth. ${ }^{17}$

Formally, the 3-period limit cycle in the growth rate depicted in Figure 3, is summarized by a triplet of growth rates, $\gamma_{a}, \gamma_{b}, \gamma_{c}$ that satisfies the intratemporal optimality linkages given by

$$
\begin{aligned}
& \frac{\left(\frac{\Lambda}{A}\left(1-\delta_{o}+\delta_{y}\right)-\delta_{y}\right)\left(A-\gamma_{b}\right) \gamma_{a}}{\left(1-\theta_{y}\right)(1-\alpha) A-\alpha A \theta_{o}-\left(1-\theta_{y}\right) \gamma_{a}}=z, \\
& \frac{\left(\frac{\Lambda}{A}\left(1-\delta_{o}+\delta_{y}\right)-\delta_{y}\right)\left(A-\gamma_{c}\right) \gamma_{b}}{\left(\left(1-\theta_{y}\right)\left((1-\alpha) A-\gamma_{b}\right)+\left(1-\theta_{y}+\theta_{o}\right)\left(\alpha A-\frac{\Lambda}{A}\left(A-\gamma_{b}\right)-\theta_{o} \alpha A\right)\right.}=z,
\end{aligned}
$$

and

$$
\frac{\left(\left(1-\delta_{o}\right) \alpha A-\delta_{y}(1-\alpha) A+\delta_{y} \gamma_{a}\right) \gamma_{c}}{\left(\left(1-\theta_{y}\right)\left((1-\alpha) A-\gamma_{c}\right)+\left(1-\theta_{y}+\theta_{o}\right)\left(\alpha A-\frac{\Lambda}{A}\left(A-\gamma_{c}\right)\right)-\theta_{o} \alpha A\right)}=z .
$$

Under parametric conditions, there exists a triplet $\left(\gamma_{a}, \gamma_{b}, \gamma_{c}\right)$, the simultaneous solution to $(25)-(27) .{ }^{18}$ An example of such a cycle is given below. ${ }^{19}$

\footnotetext{
${ }^{17}$ At various points earlier, we have noted the importance of assuming $\delta_{y}>0$ - the presence of rejuvenile behavior. For if $\delta_{y}=0$ was true, the law of motion would have no continuous segments in quadrants SW and SE and hence cycles, such as the one illustrated in Figure 3, that rely on "bouncing off" momentary equilibrium points in quadrants SW and SE would be impossible.

${ }^{18}$ These individual segments of momentary equilibria (depicted in the four quadrants of Figure 3) are reminiscent of the notion of "Euler equation branching" in Stockman, 2010. Stockman notes that in his study, "each branch alone will not imply interesting dynamics", but switching between branches allows for more intricate dynamics, and even, chaos. In our case, some branches cannot support dynamics on their own, but with the help of other branches, one can generate interesting dynamics, as in Figure 3. And although we do not pursue this link of inquiry, we conjecture that our system can support sunspot equilibria.

${ }^{19}$ The law of motion across all four quadrants is continuous everywhere; as noted earlier, though, it is
} 
Example 1 Let $\alpha=1 / 3, \beta=1, \sigma=2 / 3, A=1.75, \theta_{y}=1 / 3, \theta_{o}=1 / 3, \delta_{y}=2 / 3$, $\delta_{o}=1 / 2$, and $\lambda=0.2$. The unique steady-state growth rate is 0.78209 and the critical growth rate for bequests $\gamma_{c e}=0$.86303. A dynamically-valid equilibrium sequence, that is a limit cycle of periodicity three, is summarized by the triplet $\left(\gamma_{a}, \gamma_{b}, \gamma_{c}\right)=$ (0.72924, 1.15993, 1.72973), the simultaneous solution to (25)-(27).

The cycle is illustrated in the four-diagram panel below.

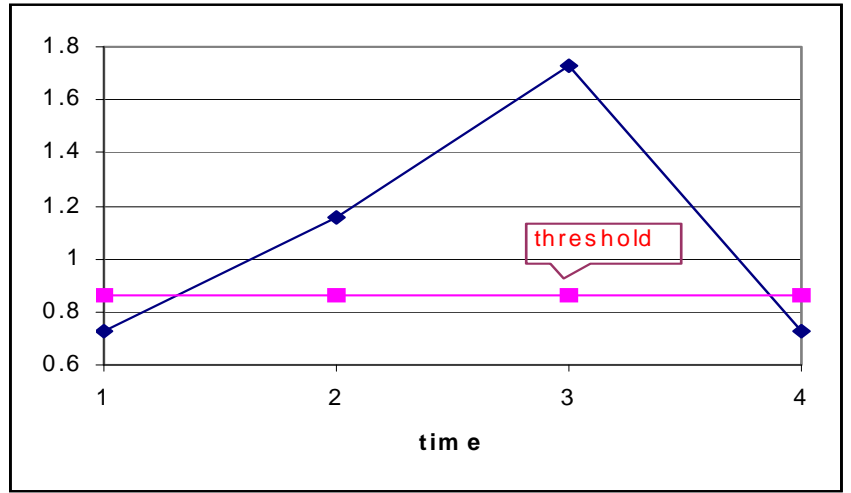

The growth rate

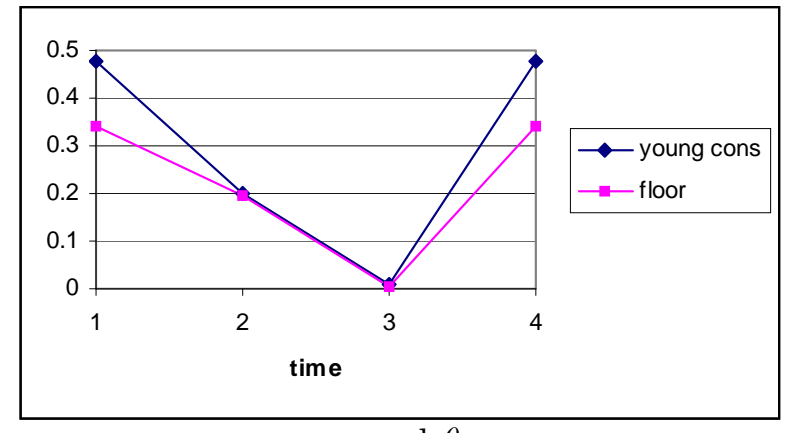

$c$ and $\theta$

Figure 4: The 3-cycle in Example 1

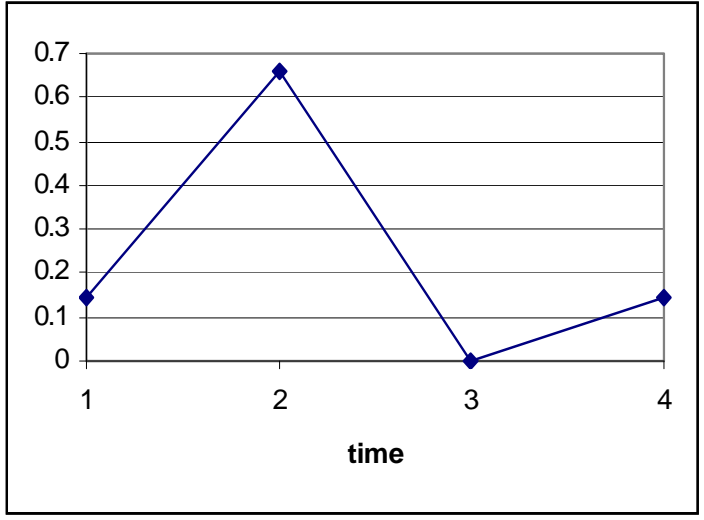

bequests

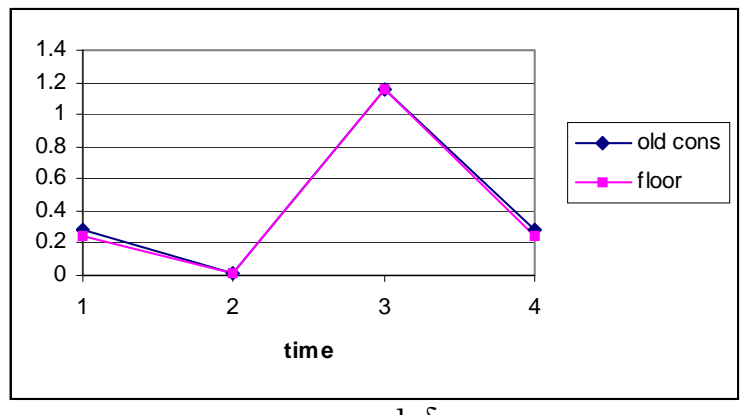

$x$ and $\delta$

In both the benchmark model and the model with intergenerational consumption externalities, it is the older generation's expectation of the future growth rate that is critical not differentiable at several points. If a one-dimensional map (such as ours) is continuous and admits a three-period cycle, then by the Li-Yorke theorem (see Azariadis, 1993) existence of topological chaos is assured. By the Sarkovski theorem, cycles of all orders are possible. We do not pursue this line of inquiry here. 
in determining whether or not they leave a bequest. The future growth rate contains summary information on the relative amounts of resources committed by the young generation to current consumption and saving, which ultimately determines the marginal benefit to the old of leaving a bequest. A high level of saving (higher growth rate) means a lower level of consumption for the child and a greater marginal benefit of the bequest gift; on the other hand, a low level of savings (higher current consumption for the child) means the gift has a smaller marginal impact on the child's utility when young.

One can, loosely speaking, interpret the future growth rate as an indicator of the child's commitment to pass on resources to the future. After all, in this $A k$ framework with a fixed return to capital, the amount of resources a child has available to leave bequests to the future will depend directly on the amount of saving she commits to when young.

However, unlike in the benchmark model, in the economy with intertemporal consumption externalities, the child's decision to save more or less affects more than simply the marginal benefit of a bequest, $\lambda u^{\prime}\left(c_{t+1} ; \theta_{t}\right)$. Consider, for an example, the case in which the child has high saving. Here, the concomitant low consumption $c_{t+1}$ reduces the consumption floor $\delta_{t}$ of the child's parent, thereby reducing the marginal cost of the gift. This may enable the parent to leave bequest even in the absence of receiving an inheritance herself - or equivalently - having saved enough to raise the growth rate $\gamma_{t}$ to a level high enough to trigger a bequest from her own parent (the grandparent of the child). Similarly, low saving by the child is consistent with a parent acting selfishly (not leaving a bequest despite receiving an inheritance). Low saving (higher consumption by child) imposes a higher consumption floor on the parent, making it more difficult to pass along a gift.

Of course, as we have modeled it, these consumption externalities work both ways. In the case described immediately above, for example, the higher levels of consumption of a selfish parent imposes a higher consumption floor $\theta_{t}$ on the child, forcing the child to consume more now - save less - rendering the growth rate below the threshold $\gamma_{c e}$.

We close with a discussion on indeterminacy. From Figure 1, it is apparent that when 
$\lambda>\left(\gamma_{c e} / z\right)^{\sigma}$, there is no indeterminacy. But when $\lambda<\left(\gamma_{c e} / z\right)^{\sigma}$, a scope for indeterminacy arises. As depicted in Figure 3, the relationship between $\gamma_{t+1}$ and $\gamma_{t}$ is a correspondence in the forward dynamics. This means given the current growth rate, perfect-foresight agents may choose high or low next-period growth rates. Hence, along two equilibrium sequences that may emanate from the same initial condition, the time series of growth rates can look very different. This sort of indeterminacy is not possible in the benchmark model. Consequently, the model predicts there can be non-convergence in growth rates across countries in the sense that countries that 'look similar' at some point in time may end up looking very different in the future.

Figure 3 also contains useful information about potential non-convergence in bequestgiving behavior across countries. For instance, consider two otherwise-identical countries I and II, that differ only in their initial growth rate; I, for example, starts off in the NE quadrant and II in quadrant SW. In this case, while multiple generations in I may leave and receive bequests (as suggested by the 3 period cycle in Figure 3), those in II may forever leave nothing.

\section{Minimum consumption requirements}

Finally, we turn to the issue of whether consumption externalities are really essential to our story. At first blush, it may appear that consumption externalities add a fair bit of complexity and yet, possibly do little more than install consumption floors, $\theta$ and $\delta$, for various generations. It may seem that replacing all such externalities by a simple generational minimum consumption requirement would be sufficient to generate all the above results, including the possibility of deviant generations. Below, we argue this is not the case.

To that end, we define minimum consumption requirements (henceforth "MCR") in the following manner: $\theta_{t} \equiv \theta y_{t}$ and $\delta_{t} \equiv \delta y_{t+1}$. Notice, for these requirements to be meaningful, they must track the growing economy; otherwise, constant MCR become insignificant (and 
hence, non binding) in a growing economy. The problem of a young agent is the same as that in Section 2: maximizing (3) subject to c1-c4. Using (9)-(10), the budget constraint $\mathrm{c}-2, x_{t}+b_{t}=\alpha A k_{t+1}$, the optimal consumption and bequest choices (setting aside for the moment, the MCRs) are derived from

$$
\left[\begin{array}{cr}
-\lambda^{1 / \sigma} & 1 \\
1 & 1
\end{array}\right]\left[\begin{array}{l}
x_{t} \\
b_{t}
\end{array}\right]=\left[\begin{array}{c}
-\lambda^{1 / \sigma} \delta A k_{t+1}-(1-\alpha) A k_{t+1}+k_{t+2}+\theta A k_{t+1} \\
\alpha A k_{t+1}
\end{array}\right]
$$

Solving yields

$$
x_{t}=\frac{\left((1-\theta)+\delta \lambda^{\frac{1}{\sigma}}\right) A-\gamma_{t+1}}{1+\lambda^{\frac{1}{\sigma}}} \gamma_{t} k_{t} ; b_{t}=\frac{-\left((1-\theta)+\delta \lambda^{\frac{1}{\sigma}}-\alpha\left(1+\lambda^{\frac{1}{\sigma}}\right)\right) A+\gamma_{t+1}}{1+\lambda^{\frac{1}{\sigma}}} \gamma_{t} k_{t}
$$

from where it is clear that $b_{t} \gtreqless 0$ iff $\gamma_{t+1} \gtreqless \widetilde{\gamma}_{m c r}^{*}$ where

$$
\widetilde{\gamma}_{m c r}^{*} \equiv\left((1-\theta-\alpha)-(\alpha-\delta) \lambda^{\frac{1}{\sigma}}\right) A
$$

Installing the floors $\theta_{t}=\theta A k_{t}$ and $\delta_{t}=\delta A k_{t+1}$, it is straightforward to show that

$$
c_{t}-\theta_{t}=\left\{\begin{array}{cl}
\left((1-\alpha-\theta) A-\gamma_{t}\right) k_{t} & \text { if } \gamma_{t} \leq \widetilde{\gamma}_{m c r}^{*} \\
\left(\left((1-\theta-\delta) A-\gamma_{t}\right) \frac{\lambda^{\frac{1}{\sigma}}}{1+\lambda^{\frac{1}{\sigma}}}\right) k_{t} & \text { if } \gamma_{t}>\widetilde{\gamma}_{m c r}^{*}
\end{array}\right.
$$

and

$$
x_{t}-\delta_{t}=\left\{\begin{array}{cl}
(\alpha-\delta) A \gamma_{t} k_{t} & \text { if } \gamma_{t+1} \leq \widetilde{\gamma}_{m c r}^{*} \\
\left(\frac{(1-\theta-\delta) A-\gamma_{t+1}}{1+\lambda^{\frac{1}{\sigma}}}\right) \gamma_{t} k_{t} & \text { if } \gamma_{t+1}>\widetilde{\gamma}_{m c r}^{*}
\end{array}\right.
$$

From these, we gather restrictions needed for the growth rates to be economically valid: $\alpha \geq \delta$ and $(1-\theta-\delta) A \geq \gamma_{t}$. Using the above expressions and conditions, we are able to prove the following:

Proposition 4 Either the parameter restriction $z \lambda^{\frac{1}{\sigma}}>\widetilde{\gamma}_{m c r}^{*}$ holds, in which case bequests are given and received in every period, or $z \lambda^{\frac{1}{\sigma}}<\widetilde{\gamma}_{m c r}^{*}$ holds, and no bequests are given or received in any period. 
A proof is provided in the appendix. As Proposition 4 indicates, the parameter restrictions $z \lambda^{\frac{1}{\sigma}}>\widetilde{\gamma}_{m c r}^{*}$ and $z \lambda^{\frac{1}{\sigma}}<\widetilde{\gamma}_{m c r}^{*}$ are mutually exclusive and preclude the coexistence of equilibria with positive bequests alongside those with zero bequests. Such an economy "qualitatively" behaves in an almost-identical manner to the benchmark economy of Section 3, one without any consumption externalities.

\section{Conclusion}

This paper extends the existing literature on the operativeness of the bequest motive to models incorporating intergenerational consumption spillovers. These externalities are introduced into a standard $A k$ growth model populated by overlapping generations of agents with dynastic preferences. In our setup, an agent faces a consumption floor set by every other agent alive at that point of her life-cycle. In the benchmark economy, one without any consumption externalities, either the bequest motive is operative for all generations (in which case, Ricardian equivalence holds) or it is never operative. The possibility, that some generation may receive an inheritance but not leave a bequest, and vice versa, does not arise.

In the economy with the aforementioned consumption externalities, somewhat surprisingly, there exists a steady-state equilibrium in which inheritances are received and bequests left at each date; consequently, Ricardian equivalence holds. However, there also exists equilibria in which the bequest motive is occasionally operative. We prove the existence of "deviant" bequest-giving behavior - that is, where a generation does not follow the same sort of bequest behavior as their predecessors did. Such intergenerational variations in the generosity of bequest-giving roughly conform to popular notions of generous and stingy generations. ${ }^{20}$ They also hasten the failure of Ricardian equivalence in a man-

\footnotetext{
${ }^{20}$ There is some casual evidence suggesting a shift in parental gift-giving is currently underway. In the U.K, for example, Cowie (2005) notes "two in three adults with the means to make a bequest say they plan to enjoy life and not worry too much about leaving a legacy. This social trend has already spawned an approximate acronym - 'skiing' or Spending the Kids' Inheritance." Gokhale and Kotlikoff (2000) study
} 
ner conjectured by Abel (1987). The economy with consumption externalities also admits indeterminacies that were absent in the benchmark economy. These externalities also produces a large variety of endogenous growth cycles that were not possible in the benchmark economy. Finally, an otherwise-identical model, one in which consumption externalities are replaced by (growing) minimum consumption requirements, cannot produce any of these results.

The analysis in the current paper does not dwell much on the interaction between the production externalities coming from the technology side and the consumption externalities entering from the preference side - the subject matter of Liu and Turnovsky (2005), although not in the context of bequest giving. Similarly, we are silent on the issue of efficiency of the bequest equilibria, something that Alonso-Carrera et. al. (2008) have investigated. If some heterogeneity is allowed - some in a generation allow their children to influence their consumption but not others - then the occasionally-binding constraints on bequests would also have important implications for wealth distributions across generations. Investigation of these important topics within the context of our preferences and technology specifications is left to future research.

survey-based evidence from the U.S. and find that "among all households, the percentage of those who believe it is important to leave an estate for one's heirs has declined from 52.5 percent to 48.4 percent during the 1990s alone.... According to the latest data, only 27 percent of all households and only 22 percent of households headed by someone over 65 expect to leave a sizable bequest." 


\section{References}

[1] Abel, A., 1987. Operative gift and bequest motives. American Economic Review, 77 (5), 1037-1047.

[2] - 1988. An analysis of fiscal policy under operative and inoperative bequest motives. In: Helpman, E., Razin, A., Sadka, E. (Eds.). Economic Effects of the Government Budget. Cambridge MA: M.I.T. Press, 91-106.

[3] - 2005. Optimal taxation when consumers have endogenous benchmark levels of consumption. Review of Economic Studies 72(1), 21-42.

[4] Alonso-Carrera, J., Caballé, J., Raurich, X., 2008. Estate taxes, consumption externalities, and altruism. Journal of Public Economics 92 (7), 1751-64.

[5] Alvarez-Cuadrado, F., Long, N.V., 2009. Envy and Inequality. mimeo, McGill University

[6] Álvarez-Peláez, M.J., and A. Díaz, 2005. Minimum consumption and transitional dynamics in wealth distribution. Journal of Monetary Economics, 52, 633-667.

[7] Aiyagari, S. R., 1992. Co-existence of a representative agent type equilibrium with a non-representative agent type equilibrium. Journal of Economic Theory 57(1), 230236 .

[8] —, Greenwood, J., and Sheshadri, A. 2002. Efficient investment in children. Journal of Economic Theory 102, 290-321.

[9] Azariadis, C. 1993. Intertemporal Macroeconomics. New York: Basil Blackwell

[10] Barnett, R.C., Bhattacharya, J., 2008. Rejuveniles and growth. European Economic Review 52, 1055-1071.

[11] Barro, R. J., 1974. Are government bonds net wealth? Journal of Political Economy $82(6), 1095-1117$.

[12] Bossi, L., Porqueras, P.G., 2010 "Fiscal Policy With Intertemporally Non-Separable Preferences," ANUCBE School of Economics Working Papers 2010-512, Australian National University.

[13] Caballe, J. 1995. Endogenous Growth, Human Capital, and Bequests in a Life-Cycle Model. Oxford Economic Papers, 47(1), 156-181.

[14] Cowie, I., 2005. Baby boomers spend the kids' inheritance. The Daily Telegraph $22 / 09 / 2005$. 
[15] de la Croix, D., Michel, P. 2002. A Theory of Economic Growth, Dynamics and Policy in Overlapping Generations. Cambridge: Cambridge University Press.

[16] Diamond, P.A. 1965. National debt in a neoclassical growth model. American Economic Review 55(5), 1126-1150.

[17] Dutta, J., Michel, P., 1998. The distribution of wealth with imperfect altruism. Journal of Economic Theory 82 (2), 379-404.

[18] Fisher, W. H., Heijdra, B. J. 2009. Keeping up with the ageing Joneses. Journal of Economic Dynamics and Control 33 (1), 53-64.

[19] Gokhale, J., Kotlikoff, L. 2000. The baby boomers' mega-inheritance: myth or reality? Federal Reserve Bank of Cleveland, Economic Commentary October 1.

[20] Liu, W., Turnovsky S., 2005. Consumption externalities, production externalities, and long-run macroeconomic efficiency. Journal of Public Economics 89 (5-6), 1097-1129.

[21] Matsuyama, K. 1999. Growing through cycles. Econometrica 67 (2), 335-347.

[22] Michel, P., Thibault, E., Vidal, J., 2006. Intergenerational altruism and neoclassical growth models. In: Kolm, S., Ythier, J.M. (Eds.) Handbook on the Economics of Giving, Reciprocity and Altruism Vol. II. Amsterdam: Elsevier, 1055-1106.

[23] Michel, P., Pestieau, P. 1998. Fiscal Policy in a Growth Model with Both Altruistic and Nonaltruistic Agents, Southern Economic Journal, 64(3), 682-697

[24] Noxon, C., 2006. Rejuvenile. New York: Crown publishers.

[25] E. S. Phelps and R. A. Pollak. 1968. On second-best saving and game-equilibrium growth. Review of Economic Studies, 35, 185-199.

[26] Stockman, David. 2010. Balanced-Budget Rules: Chaos and Deterministic Sunspots, Journal of Economic Theory, 145(3), 1060-1085.

[27] Thibault, E., 2000. Existence of equilibrium in an OLG model with production and altruistic preferences. Economic Theory 15 (3), 709-715.

[28] Wälde, K., 2005. Endogenous growth cycles. International Economic Review 46 (3), 867-894.

[29] Weil, P., 1987. Love thy children: reflections on the Barro debt neutrality theorem. Journal of Monetary Economics 19(3), 377-91. 


\section{$\underline{\text { Appendix }}$}

\section{A Proof of Proposition 1}

All the information about the law of motion and its pieces are summarized in the table below.

Table A1

\begin{tabular}{|c|l|l|l|l|}
\hline Case & Intertemporal Condition & $\begin{array}{l}\text { Condition on } \\
\text { growth rates }\end{array}$ & $\begin{array}{c}\text { Inheritance } \\
\text { received }\end{array}$ & $\begin{array}{c}\text { Bequest } \\
\text { left }\end{array}$ \\
\hline A & $\gamma_{t}=\frac{A z(1-\alpha)}{z+A \alpha}$ & if $\gamma_{t}, \gamma_{t+1} \leq \gamma_{b m}$ & no & no \\
\hline B & $\gamma_{t+1}=A+z\left(1+\lambda^{1 / \sigma}\right)-\frac{z\left(1+\lambda^{1 / \sigma}\right)(1-\alpha) A}{\gamma_{t}}$ & if $\gamma_{t} \leq \gamma_{b m} \leq \gamma_{t+1}$ & no & yes \\
\hline C & $\gamma_{t}=\frac{A z \lambda^{\frac{1}{\sigma}}}{A \alpha\left(1+\lambda^{\frac{1}{\sigma}}\right)+\lambda^{\frac{1}{\sigma}} z}$ & if $\gamma_{t+1} \leq \gamma_{b m} \leq \gamma_{t}$ & yes & no \\
\hline D & $\gamma_{t+1}=A+z \lambda^{\frac{1}{\sigma}}-\frac{A z \lambda^{\frac{1}{\sigma}}}{\gamma_{t}}$ & if $\gamma_{b m} \leq \gamma_{t}, \gamma_{t+1}$ & yes & yes \\
\hline
\end{tabular}

Some work is required to verify that the above intertemporal conditions satisfy the conditions on growth rates stated in the third column of Table A1. Note that in cases A and $\mathrm{C}$ we have a simple condition on $\gamma_{t}$, while cases $\mathrm{B}$ and $\mathrm{D}$ are slightly more complicated. For case A, noting that $\gamma_{t}$ is trivially positive, we need

$$
\gamma_{t}=\frac{A z(1-\alpha)}{z+A \alpha} \leq \gamma_{b m}
$$

which with straightforward algebra can be written as

$$
\lambda^{1 / \sigma} z \leq \gamma_{b m} .
$$

For case $\mathrm{C}$, the condition is

$$
\gamma_{t}=\frac{A z \lambda^{\frac{1}{\sigma}}}{A \alpha\left(1+\lambda^{\frac{1}{\sigma}}\right)+\lambda^{\frac{1}{\sigma}} z} \geq \gamma_{b m} \Leftrightarrow \gamma_{b m} \leq \lambda^{\frac{1}{\sigma}} z .
$$

Note that these two conditions exactly contradict each other. This implies that equilibria paths can never display both cases $\mathrm{A}$ and $\mathrm{C}$.

Now consider case B. Here the constraint we must verify is $\gamma_{t} \leq \gamma_{b m} \leq \gamma_{t+1}$. First check

$$
\gamma_{b m} \leq \gamma_{t+1} \Leftrightarrow \gamma_{t} \geq \frac{(1-\alpha) z A}{z+\alpha A}
$$


Thus, for the entire constraint to be satisfied, we must have

$$
\frac{(1-\alpha) z A}{z+\alpha A} \leq \gamma_{t} \leq \gamma_{b m}
$$

It is easy to verify that $\frac{(1-\alpha) z A}{z+\alpha A} \leq \gamma_{b m}$ if and only if

$$
\gamma_{b m} \geq \lambda^{\frac{1}{\sigma}} z
$$

Comparing this expression with (28) and (29) we see that equilibrium paths can possibly display both cases $\mathrm{A}$ and $\mathrm{B}$, but never $\mathrm{B}$ and $\mathrm{C}$. That is, cases $\mathrm{A}$ and $\mathrm{B}$ are inconsistent with $\mathrm{C}$. Note however, that case $\mathrm{C}$ - where the old leave no bequest - must be followed by a case where the young receive no bequest and $\mathrm{A}$ and $\mathrm{B}$ are the only cases where the young receive no bequest. Since cases $\mathrm{A}$ and $\mathrm{B}$ are inconsistent with case $\mathrm{C}$, this implies that case $\mathrm{C}$ is inconsistent with any equilibrium path. This has the further implication that once an economy finds itself in case $\mathrm{D}$ with bequest both received and given, it must stay there forever, since there are no valid equilibrium points where bequest are received but not given (case $\mathrm{C}$ ).

Finally we turn out attention to case D. First note that

$$
\gamma_{t+1} \geq \gamma_{b m} \Leftrightarrow \gamma_{t} \geq \frac{A z \lambda^{\frac{1}{\sigma}}}{z \lambda^{\frac{1}{\sigma}}+\alpha A\left(1+\lambda^{1 / \sigma}\right)} .
$$

Note that there always are valid values of $\gamma_{t}$ since $\frac{A z \lambda^{\frac{1}{\sigma}}}{z \lambda^{\frac{1}{\sigma}}+\alpha A\left(1+\lambda^{1 / \sigma}\right)}<A$.

Now consider the intertemporal condition. This has two fixed points. One at $z \lambda^{\frac{1}{\sigma}}$ and another, economically invalid one at $A .^{21}$ To establish which points may be part of a valid equilibrium path we need to analyze the dynamic properties of the intertemporal condition. It is easily seen that

$$
\begin{aligned}
\frac{\partial \gamma_{t+1}}{\partial \gamma_{t}} & =\frac{A z \lambda^{\frac{1}{\sigma}}}{\gamma_{t}^{2}}>0 \\
\frac{\partial^{2} \gamma_{t+1}}{\partial \gamma_{t}^{2}} & =-2 \frac{A z \lambda^{\frac{1}{\sigma}}}{\gamma_{t}^{3}}<0,
\end{aligned}
$$

such that the intertemporal condition is increasing in $\gamma_{t}$ and concave to the origin. Furthermore the slope at $z \lambda^{\frac{1}{\sigma}}$ is given by

$$
\left.\frac{\partial \gamma_{t+1}}{\partial \gamma_{t}}\right|_{z \lambda^{\frac{1}{\sigma}}}=\frac{A z \lambda^{\frac{1}{\sigma}}}{\left(z \lambda^{\frac{1}{\sigma}}\right)^{2}}=\frac{A}{z \lambda^{\frac{1}{\sigma}}} .
$$

\footnotetext{
${ }^{21}$ At this steady state, $x=c=0$ and these points have infinite marginal utility, and hence would never be valid.
} 
This leaves two possibilities: Either $z \lambda^{\frac{1}{\sigma}}>A$, in which case $z \lambda^{\frac{1}{\sigma}}$ is economically invalid, or $z \lambda^{\frac{1}{\sigma}}<A$ which implies that $\left.\frac{\partial \gamma_{t+1}}{\partial \gamma_{t}}\right|_{z \lambda^{\frac{1}{\sigma}}}>1$ such that $z \lambda^{\frac{1}{\sigma}}$ is an unstable fixed point and $A$ is stable. Since we demonstrated above that once in case D we must stay in case D, we can rule out all growth rates higher than $z \lambda^{\frac{1}{\sigma}}$, as these economies would eventually converge to the (invalid) fixed point $\mathrm{A}$. This implies that for $D$ to contain any points that could be part of an equilibrium path, we need $\gamma_{b m}<z \lambda^{\frac{1}{\sigma}}$. This in turn is inconsistent with cases A and $\mathrm{B}$, so we have either A and B or D. Now focus on case D with growth rates greater than $\gamma_{b m}$ but less than $z \lambda^{\frac{1}{\sigma}}$. Note that for

$$
\gamma_{t}=\frac{A z \lambda^{\frac{1}{\sigma}}}{z \lambda^{\frac{1}{\sigma}}+\alpha A\left(1+\lambda^{1 / \sigma}\right)}>\gamma_{b m}
$$

we have $\gamma_{t+1}=\gamma_{b m}$. Thus, our intertemporal condition starts out below the 45-degree line and crosses it once at the unstable SS $z \lambda^{\frac{1}{\sigma}}$. If $\gamma_{t}<z \lambda^{\frac{1}{\sigma}}$, because the fixed point is unstable, we will eventually enter the range where bequest are received but not given (Case C)). Since there are no valid points in this range, this rules out Case D with $\gamma_{t}<z \lambda^{\frac{1}{\sigma}}$ and the only valid point is the steady state $z \lambda^{\frac{1}{\sigma}}$.

Finally note that since cases B and D are incompatible, this renders case B invalid, since in case $\mathrm{B}$ a bequest is given, the next period must involve receipt of a bequest. This only happens in cases $\mathrm{C}$ and $\mathrm{D}$, which are incompatible with case B. Thus, we are left with either case A or case D. This leaves us with two possibilities:

$$
z \lambda^{\frac{1}{\sigma}}<\gamma_{b m} \text { and } \gamma=\frac{A z(1-\alpha)}{z+A \alpha} \text { (no bequests given or received) }
$$

or

$$
z \lambda^{\frac{1}{\sigma}}>\gamma_{b m} \text { and } \gamma=z \lambda^{\frac{1}{\sigma}} \text { (bequests given and received). }
$$

\section{B Proof of Proposition 4}

In the case where no bequests are left at each date, it is easy to check that $\gamma_{t}=\frac{z(1-\alpha-\theta) A}{(\alpha-\delta) A+z}$ $\forall t$ and that $\gamma_{t}<\widetilde{\gamma}_{m c r}^{*}$ if $\lambda^{\frac{1}{\sigma}} z<\widetilde{\gamma}_{m c r}^{*}$. In the case where bequests are left each date, we have

$$
\left(\frac{(1-\theta-\delta) A-\gamma_{t+1}}{1+\lambda^{\frac{1}{\sigma}}}\right) \gamma_{t} k_{t}=z\left(\left(\frac{(1-\theta-\delta) A-\gamma_{t}}{1+\lambda^{\frac{1}{\sigma}}} \lambda^{\frac{1}{\sigma}}\right) k_{t}\right)
$$

from where it is clear that

$$
\gamma_{t+1}=-\frac{z \lambda^{\frac{1}{\sigma}}(1-\theta-\delta) A}{\gamma_{t}}+z \lambda^{\frac{1}{\sigma}}+(1-\theta-\delta) A
$$


There are two steady state solutions to (30), the infeasible $(1-\theta-\delta) A$ and $z \lambda^{\frac{1}{\sigma}}$. This implies, that either there exists a valid steady state in which bequests are left or one in which they are never left, and conditions for the existence of one or the other are mutually exclusive.

What about other intertemporal linkages? Consider the case where no bequest is received but bequest is left. This happens when $\gamma_{t} \leq \widetilde{\gamma}_{m c r}^{*}$ and $\gamma_{t+1}>\widetilde{\gamma}_{m c r}^{*}$. Then, we have

$$
\left(\frac{(1-\theta-\delta) A-\gamma_{t+1}}{1+\lambda^{\frac{1}{\sigma}}}\right) \gamma_{t} k_{t}=z\left((1-\alpha-\theta) A-\gamma_{t}\right) k_{t}
$$

which simplifies to

$$
\gamma_{t+1}=-\frac{z(1-\alpha-\theta)\left(1+\lambda^{\frac{1}{\sigma}}\right) A}{\gamma_{t}}+z\left(1+\lambda^{\frac{1}{\sigma}}\right)+(1-\theta-\delta) A .
$$

It remains to verify that indeed $\gamma_{t} \leq \widetilde{\gamma}_{m c r}^{*} \leq \gamma_{t+1}$ holds. Note from (31) that $\frac{\partial \gamma_{t+1}}{\partial \gamma_{t}}>0$ holds; so at $\gamma_{t}=\widetilde{\gamma}_{m c r}^{*}, \gamma_{t+1} \geq \widetilde{\gamma}_{m c r}^{*}$ must hold, otherwise $\gamma_{t} \leq \widetilde{\gamma}_{m c r}^{*} \leq \gamma_{t+1}$ can never hold. Simple algebra reveals that $\gamma_{t+1} \geq \widetilde{\gamma}_{m c r}^{*} \Leftrightarrow z \lambda^{\frac{1}{\sigma}} \leq \widetilde{\gamma}_{m c r}^{*}$.

Finally, focus attention on the case where a bequest is received but not given. This happens when $\gamma_{t}>\widetilde{\gamma}_{m c r}^{*}$ and $\gamma_{t+1} \leq \widetilde{\gamma}_{m c r}^{*}$. In this case, it is easy to check that

$$
\gamma_{t}=\frac{(1-\delta-\theta) A}{z \lambda^{\frac{1}{\sigma}}+A(\alpha-\delta)\left(1+\lambda^{\frac{1}{\sigma}}\right)} \lambda^{\frac{1}{\sigma}} z
$$

and that $\gamma_{t}>\widetilde{\gamma}_{m c r}^{*}$ holds when $z \lambda^{\frac{1}{\sigma}}>\widetilde{\gamma}_{m c r}^{*}$.

The upshot is the following. If $z \lambda^{\frac{1}{\sigma}}>\widetilde{\gamma}_{m c r}^{*}$, we have two possibly valid cases. One is the case where bequests are given and received each period; the other is a case where bequests are received but never given. If $z \lambda^{\frac{1}{\sigma}}<\widetilde{\gamma}_{m c r}^{*}$, we again have two possibly valid cases. One is the case with no bequests given or received ever; the other is the case where no bequests are received, but bequests are left. 